Linköping Studies in Science and Technology, Dissertation No. 1133

\title{
INDUSTRIAL SYMBIOSIS \\ IN THE SWEDISH FOREST INDUSTRY
}

ANNA WOLF

Division of Energy Systems

Department of Management and Engineering

Linköping Institute of Technology,

SE-581 83 Linköping, Sweden

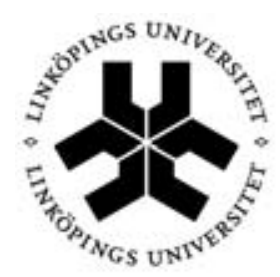


ISBN: 978-91-85895-86-1

ISSN: 0345-7524

Printed in Sweden by LiU-Tryck, Linköping 2007. 
This thesis is based on work conducted within the interdisciplinary graduate school Energy Systems. The national Energy Systems Programme aims at creating competence in solving complex energy problems by combining technical and social sciences. The research programme analyses processes for the conversion, transmission and utilisation of energy, combined together in order to fulfil specific needs.

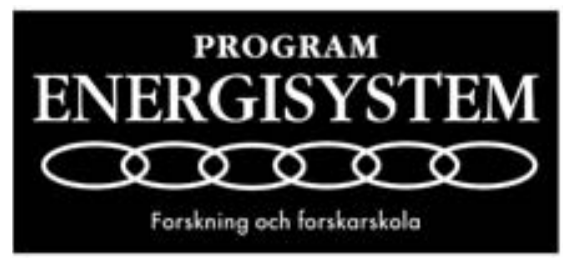

The research groups that participate in the Energy Systems Programme are the Division of Solid State Physics at Uppsala University, the Division of Energy Systems at Linköping Institute of Technology, the Department of Technology and Social Change at Linköping University, the Department of Heat and Power Technology at Chalmers University of Technology in Göteborg as well as the Division of Energy Processes at the Royal Institute of Technology in Stockholm.

www.liu.se/energi 



\begin{abstract}
The research presented in this thesis draws upon the research field of Industrial Ecology, in particular Industrial Symbiosis, assuming that it is possible for an industry to increase its product value and simultaneously decrease its use of resources and production of waste material if its material and energy flows are effectively integrated into a larger system. The objective of this work was to apply the framework of IS to the Swedish forest industry, both to gain empirical evidence, which can be used for further conceptual development, and to evaluate how the industrial symbiosis approach can contribute to the forest industry. Occurrence, development and evaluation of integrated systems have been addressed. The results are mainly based on case studies. To evaluate the economic and environmental effects of industrial symbiosis the MIND method, which is an optimization program based on mixed integer linear programming, has been used.
\end{abstract}

It is argued that several cases of industrial symbiosis exist within the Swedish forest industry today, and in the cases studied the integration is considered fruitful from the companies' point of view. The human dimensions of increased integration are discussed, and it is seen that the conditions for implementation differ depending on the type of system considered. The most important conditions common for all systems are a positive attitude from the companies involved, willingness to act and power relations. Lack of resources, imperfect environmental regulations, time frames and the risks involved when adopting new technologies were among the barriers identified. The results from the evaluation indicate some support to the theories that industrial symbiosis can have benefits both from an economical and an environmental point of view. However, it is seen that the results vary considerably depending on the assumptions made and it is concluded that great care should be taken in choosing method and boundary conditions depending on the case and the nature of the study, the MIND method being one possible method.

Language: English

Keywords: forest industry, integration, industrial symbiosis, evaluation, human dimensions, MIND method 


\section{SAMMANFATTNING}

Forskningen som presenteras i denna avhandling anknyter till forskningsfältet Industriell Ekologi och då särskilt den gren som kallas Industriell Symbios (IS). Inom IS förordas att ett företag kan öka produktionen och samtidigt minska resursanvändningen genom att effektivt integrera energioch materialflöden $\mathrm{i}$ ett större system. Utbyte av tex spillvärme och biprodukter mellan olika industrier kan minska behovet av primärvärme och råmaterial. Syftet med avhandlingen är att undersöka hur det teoretiska ramverk som byggts upp inom IS kan appliceras på den svenska skogsindustrin. Detta leder till empiriskt material som kan bidra till vidare teroriutveckling, samt ger en insikt om hur IS kan bidra till resurseffektiviteten inom skogsindustrin. Avhandlingen behandlar teman som existens, utveckling och utvärdering av integrerade system. Främst baseras resultaten på fallstudier, bl a från Kisa, Mönsterås, Värö och Forssjöbruk. För att utvärdera ekonomiska och miljömässiga aspekter (främst $\mathrm{CO}_{2}$ utsläpp) har även ett optimeringsprogram använts (MIND).

Resultaten visar att flera fall av industriell symbios existerar inom svensk skogsindustri redan idag och att samarbetena betraktas som gynnsamma av de ingående parterna. Det visas även att förutsättningarna för att implementera IS varierar beroende på vilken typ av system som avses. De viktigaste gemensamma nämnarna för alla system är en positiv attityd från företagens sida, en vilja att agera, och maktrelationer i företagen. Brist på resurser, bristfällig miljölagstiftning, tidsramar för investeringar samt risker med att satsa på ny teknik är de viktigaste hindren som identifierats. Resultaten från utvärderingen indikerar att IS kan ha fördelar både ur ett ekonomiskt och miljömässigt perspektiv. Dock visas tydligt att resultaten varierar avsevärt beroende på vilka antaganden som görs och slutsatsen är därför att ett noggrannt val av metod, systemgräns och randvillkor är av yttersta vikt och varierar beroende på studiens syfte.

Språk: engelska

Nyckelord: skogsindustri, integration, industriell symbios, utvärdering, implementering, MIND-metoden 


\section{LIST OF APPENDED PAPERS}

The thesis is based on the following papers, referred to by the Roman numerals I - VI. The papers are appended at the end of this thesis.

I Wolf A, Vidlund A, Andersson E. Energy efficient pellet production in the forest industry - A study of obstacles and success factors. Biomass and Bioenergy, Vol. 30, No. 1, pp. 38-45, 2006

II Wolf A, Eklund M, Söderström M. Developing integration in a local industrial ecosystem - An explorative approach. Business Strategy and the Environment, Vol. 13, No. 6, pp. 442-455, 2007

III Wolf A, Eklund M, Söderström M. Towards cooperation in industrial symbiosis: considering the importance of the human dimension. Progress in Industrial Ecology - An International Journal, Vol. 2, No. 2, pp. 185199, 2005

IV Wolf A, Petersson K. Industrial Symbiosis in the Swedish Forest Industry. Accepted for publication in Progress in Industrial Ecology - An International Journal, 2007

V Karlsson M, Wolf A. Using an optimisation model to evaluate industrial symbiosis in the forest industry. Accepted for publication in Journal of Cleaner Production, 2007

VI Wolf A, Karlsson M. Can the environmental benefits of Industrial Symbiosis be evaluated? Discussion and demonstration of an approach. Presented at the 13th Conference of Sustainable Development Research, June 10-12, 2007. Submitted for publication in a special issue of Progress in Industrial Ecology - An International Journal.

A co-author statement on each of the papers is given in section 1.3 of this thesis. 
Related publications not included in this thesis:

Energieffektiv biobränsleförädling i skogsindustrin

Andersson A, Frimanzon A, Vidlund A

Program Energisystem, Arbetsnotat Nr 24, ISSN 1403-8307, 2003, in

Swedish

Skogsindustriellt Ekosystem i Kisa

Eklund M, Söderström M, Wolf A

LiTH-IKP-R-1351, 2004, in Swedish 


\section{ACKNOWLEDGEMENTS}

The work I present in this thesis was carried out at the Division of Energy Systems at the Department of Management and Engineering, Linköping University, and my background is in chemical engineering. I am also, however, part of an interdisciplinary graduate school, the Energy Systems Programme. The Energy Systems Programme aims at 'creating competence in solving complex energy problems by combining technical and social sciences' and meeting, discussing and collaborating with colleagues from other disciplines has had a profound impact on my work. I would like to thank everyone who helped me accomplish this thesis:

Associate Professor Mats Söderström, my principal supervisor, who has helped and encouraged me during this work and Dr Magnus Karlsson, my cosupervisor at the department for his valuable comments, often at short notice. This thesis would not have been possible without the ideas, knowledge and moral support of my co-supervisor Professor Mats Eklund. Professor Staffan Laestadius, who acted as my interdisciplinary supervisor for a period, is acknowledged and I am also grateful to Dr Pål Börjesson who gave me new insights about my early work when he was external examiner for my licentiate thesis, and to Dr Fredrik von Malmborg who provided useful comments on an early draft of this thesis.

I would also like to thank all my colleagues at the energy system division and in the energy systems programme for their support and inspiring discussions and arguments. I am especially grateful to my co-authors Anna Vidlund, Eva Andersson and Kenth Petersson for a fruitful co-operation; and to Professor Mats Westermark, Professor Per Alvfors and all the others at the division of Energy Processes at KTH for solving my long distance commuting problems.

The financial support provided by the Swedish Energy Agency is gratefully acknowledged and I would like also to extend my sincere gratitude to the companies involved in the case studies for valuable information. 
I thank all the members of my family without whom I would not be the person I am today. I am happy that I have you all, and I am happy that there are so many of you that I don't have room to mention everyone here! Also, all the friends who have supported me throughout the work, especially Dr. Wallström (without you I would never have thought I could either write a scientific paper or pull on a pair of panty-hose) \& Anders, Fredrik \& Maria, Maja and Jocke (who helped me through graduation in the first place). Thanks also to Rebecca and the girls in "pappagruppen" and "augustibebisar", who helped me survive maternal leave. Last but not least: Jens, your support and love I could not have done without; and Ebba, thank you for being the light of my life! 


\section{THESIS OUTLINE}

The thesis consists of an introduction to, and a summary of, the six appended research papers. Some additional material is also presented. The thesis is laid out as follows:

Chapter 1 gives a brief introduction and background to the thesis work. The subject of the study is introduced and the chapter ends with a paper overview and co-author statement along with a description of the research journey conducted and the connection between the papers.

Chapter 2 presents some previous research on industrial symbiosis and related research from different research fields.

Chapter 3 presents the scope and objectives of this work.

Chapter 4 addresses the methodologies used.

Chapter 5 includes some historical perspectives, mainly based on a literature review, and some lessons learned from the case studies. The results from paper IV regarding the situation today are also presented.

Chapter 6 presents and discusses the results concerning evaluation of industrial symbiosis.

Chapter 7 is based on the non-technical parts of the results from papers I-III. The chapter discusses how the ideas of industrial symbiosis could be implemented and how industrial ecosystems could be developed.

Chapter 8 discusses and summarizes the general conclusions found during the course of this thesis and addresses some areas of interest for further research. 


\section{TABLE OF CONTENTS}

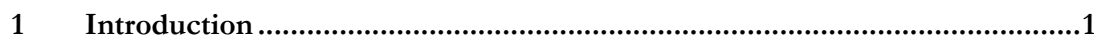

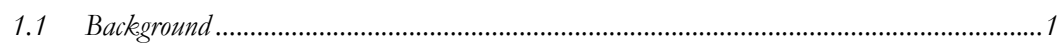

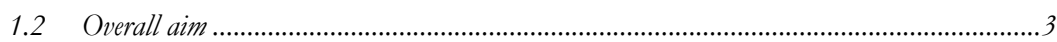

1.3 Paper overview and research journey ............................................................................

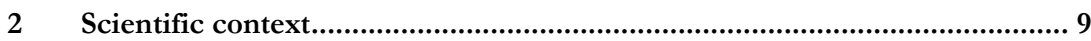

2.1 Industrial ecology and industrial symbiosis ...................................................................

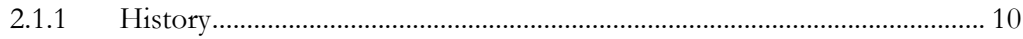

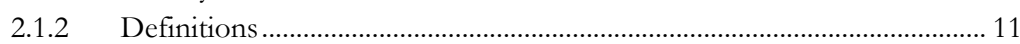

2.1.3 Industrial symbiosis in practice ………....................................................... 14

2.1.4 Development and organization ............................................................. 15

2.1.5 Industrial symbiosis in the forest industry ............................................... 17

2.1.6 Integrated biofuel upgrading..................................................................... 18

2.1.7 Evaluation of industrial symbiosis ……………………………………...... 19

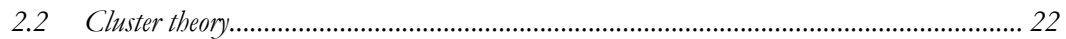

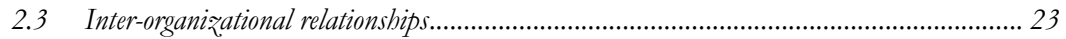

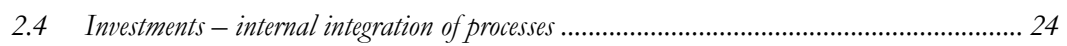

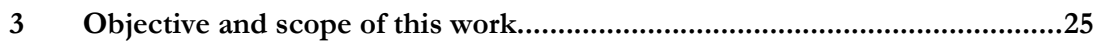

3.1 Objective and research questions............................................................................ 25

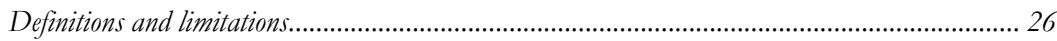

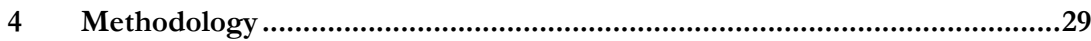

4.1 Approaches......................................................................................................... 29

4.2 Case studies ............................................................................................................. 30

4.3 Inventory of industrial symbiosis in the Swedish forest industry ........................................ 32

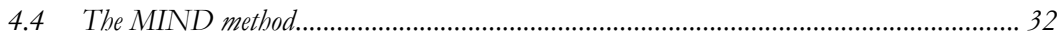

5 Industrial symbiosis in the Swedish forest industry - development and

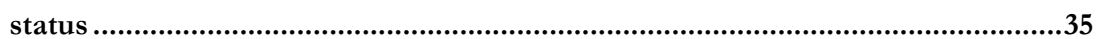

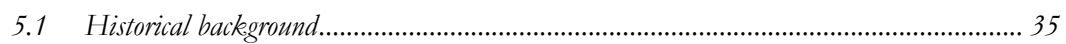

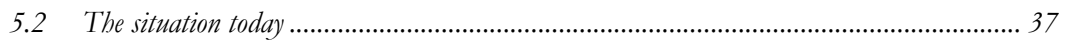

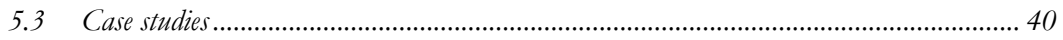

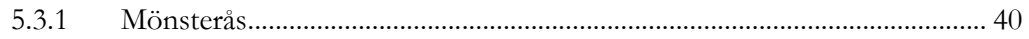

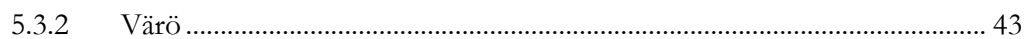




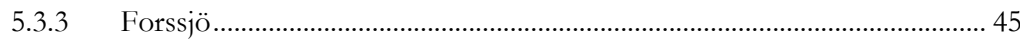

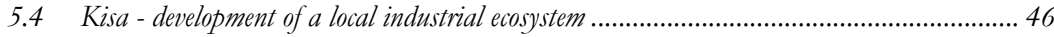

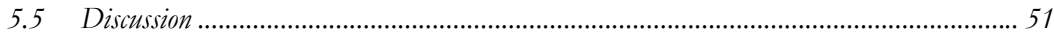

$6 \quad$ Evaluating the success of industrial symbiosis ...........................................53

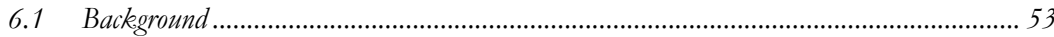

6.2 Qualitative evaluation of the cases................................................................................. 55

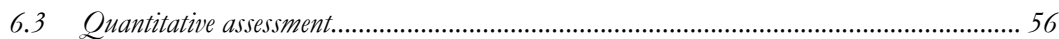

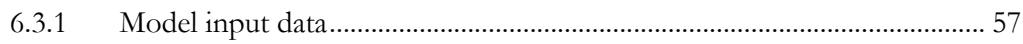

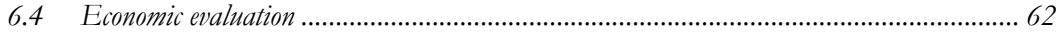

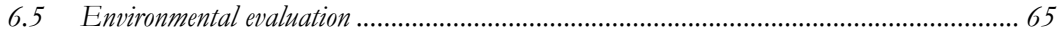

6.6 Discussion and conclusions from the evaluation.............................................................. 66

$7 \quad$ Getting there - on the implementation of industrial symbiosis ...................69

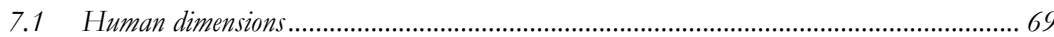

7.2 Strategies for development of industrial symbiosis initiatives .............................................. 73

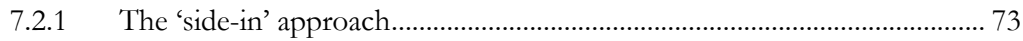

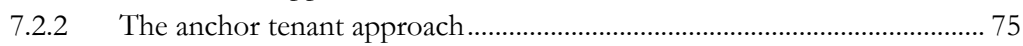

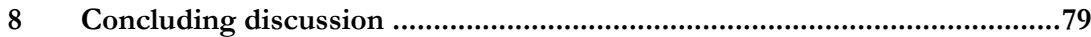

8.1 Summary of conclusions............................................................................................... 79

8.1.1 Can industrial ecosystems or other examples of integration be found in the Swedish forest industry using the industrial symbiosis approach? ..................... 79

8.1.2 How have the systems evolved, how can the existing systems be further developed and how can the knowledge be implemented in new systems?

8.1.3 How can the success of industrial ecosystems or other examples of integration be evaluated from an economic and environmental point of view?..... 81

8.1.4 Research contribution in the light of the objective .................................... 82

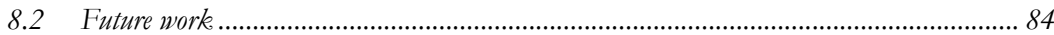

Notes

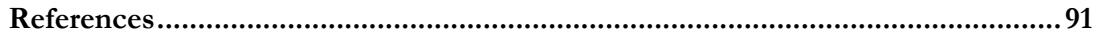




\section{INTRODUCTION}

In this chapter, a background to the thesis work is given. The subject of the study is introduced along with the overall aim, a paper overview, co-author statement and a description of the research journey conducted and the connection between the papers.

\subsection{Background}

Historically, industrial development has led to a changed and often increased environmental impact. The challenge we are facing today is to combine economic development with a decrease in environmental pressure. In the light of the growing concern about climate change, it is obvious that an important part of the environmental pressure from industry is connected to its energy use. The use of fossil fuels contributes to the rising concentration of greenhouse gases in the atmosphere. Moreover, dependence on fossil fuels is not a long-term solution since they are a limited resource. One solution is to substitute renewable energy sources, such as biofuel or solar and wind power, for fossil fuels. However, it must be remembered that most renewable energy sources are scarce (such as biofuel which can only be considered renewable as long as it is used at a slower pace than it can be regrown) and many technologies are not yet fully deployed (such as solar and wind power) or may have other negative effects on the environment. Another important factor as regards environmental pressure from industry is the use of physical resources and the production of waste. Energy use and material use are often closely connected and to achieve better resource economy it is thus important to ensure that all resources are used as efficiently as possible. 
Means to increase efficiency and avoid sub-optimizations can be developed by expanding the system boundaries and adopting a broader systems view. A company may increase its product value and simultaneously decrease its use of resources and production of waste if its material and energy flows are effectively integrated into a larger system. No company is an island; it is part of a supply chain, has a geographical location, and is embedded in a larger system with several actors. The character and the extent of a company's environmental impact are to a large extent determined in this interaction between companies and other external actors (c.f. Clift and Wright, 2000). In the literature on industrial symbiosis (IS), where exchanges of material and energy have been evaluated and discussed for almost 20 years, it is usually assumed that integration of companies through such exchanges may lead to a more efficient use of material and energy as well as financial benefits for the entities involved (e.g. Chertow, 2000; Lifset and Graedel, 2002). However, ideas which are profitable from an economic and environmental point of view are not always implemented, and this can sometimes have rational explanations.

The focus in this thesis is on industrial symbiosis in the forest industry, which in this study is defined to include the pulp, paper and wood mechanical industries. The forest industry is one of the most important industries in Sweden and has a significant role in the Swedish energy system. The forest industry and forestry account for 11 to $12 \%$ of the employment and added value in the Swedish industry, and around $11 \%$ of the country's exports. In 2006, there were 47 paper mills, 44 pulp mills, 170 sawmills $\left(>10,000 \mathrm{~m}^{3}\right.$ / year) and 8 particle board mills in Sweden (Swedish Forest Industries Federation 2007a).

The pulp and paper mills use about 22 TWh electricity and 500,000 $\mathrm{m}^{3}$ oil annually (Swedish Forest Industries Federation, 2007a) and account for 49\% of the total amount of energy used by industry in Sweden (SEA, 2006). The forest industry is also an important user of woody biomass and a producer of by-product biofuel. The pulp mills used $7 \mathrm{TWh}$ and the wood working industry 5 TWh of woody biofuel by-products for energy uses in 2005. In 
addition, 38 TWh of black liquors were used in the pulp and paper mills. In Sweden, the total use of biofuel, peat and waste material for energy purposes was 112 TWh the same year (SEA, 2006).

Several Swedish studies indicate that increased integration in the forest industry has the potential to create more efficient and sustainable systems. Andersson et al. (2003) and Vidlund (2004) concluded that integrated biofuel upgrading in the forest industry can save biofuel and reduce $\mathrm{CO}_{2}$ emissions. Nyström and Cornland (2003) describe increased integration in the forest industry sector as a condition for sustainability in a model scenario and conclude that the sector could be a net supplier of energy if integration is increased along with other improvements.

\subsection{Overall aim}

Much of the IE and IS research has been focused on conceptual development and it is important to test and question the theories since further development needs to be done in the light of critical analysis. Harper and Graedel (2004) suggest that IE needs to test its frameworks on real life cases and make use of that learning to develop further. The overall aim of this work is to contribute to the IS field with the knowledge gained through applying its frameworks to the forest industry. It also endeavours to contribute to the knowledge of how to increase resource efficiency in the forest industry by using the industrial symbiosis framework. The selection of the forest industry as a case study is motivated by the importance of this sector in Sweden and by the dependence on renewable fuels and raw materials which may contribute to the overall goals of sustainability that IE endeavours to achieve.

\subsection{Paper overview and research journey}

The contribution of the author to each of the appended papers I-VI is described below in the paper overview. I was the main author for papers I-IV; for papers V-VI, Magnus Karlsson and I shared the work equally between us. As my supervisor, Mats Söderström has read all papers and contributed with comments and critique. As my co-supervisors, Staffan Laestadius has read and provided valuable critique on paper I, Magnus Karlsson on paper II-IV, and Mats Eklund on papers IV-VI. 


\section{Paper I}

The first year of my work as a PhD student was mainly dedicated to courses in the interdisciplinary graduate school, the Energy Systems Programme. My participation in those courses gave me time to study the background of my work, and to consider the research questions I would seek to answer. However, my time in the energy systems programme also made possible exchanges of ideas as well as some fruitful co-operations with other $\mathrm{PhD}$ students. Paper I is based on such a project, conducted in co-operation with Anna Vidlund, KTH and Eva Andersson, Chalmers. The research concerned integrated biofuel upgrading in the forest industry and three case studies were made. During the initial project it was seen that the possibilities for heat recovery can be improved if the upgrading process is integrated with other energy-intensive processes, for example a pulp mill or a sawmill, in a biofuel combine. The work presented in paper I evaluates obstacles and success factors for forming such biofuel combines with the forest industry. Driving forces identified include an excess of by-products and waste heat, together with an existing need for investments. The market and the ownership structures were other important factors identified.

I performed the interviews and was responsible for the case study on obstacles and success factors and also did the major part of the writing. Anna Vidlund and Eva Andersson conducted the major part of the economical calculations. Scope, assumptions, analysis, and discussion we shared between us.

\section{Papers II-III}

The initial working idea of my project concerned only energy exchanges. However, aiming at systems thinking, it soon became clear that material exchanges were not to be ignored, especially since most by-products in the forest industry could be counted both in tons and MWh. My co-supervisor at that time, Professor Mats Eklund, introduced me to the concept of industrial ecology, and the objectives of my research were revised to concern industrial symbiosis. Together with Mats Eklund and my supervisor Mats Söderström, I took part in a LEGS (Local Employment and Growth Strategies) project resulting in Papers II-III. Both papers are based on a case study conducted in 
the municipality of Kisa, including the cooperation between forest industry, municipality and energy service company aiming at investigating if connections of material and energy exchanges can be found and developed into a local industrial ecosystem, and what the obstacles and success factors for such development would be. The results from the case study were divided into two research papers, since the aim of the study was twofold, and since it would have been difficult to present the different results in one paper maintaining a clear main theme. In paper II, the approach to develop a local industrial ecosystem was presented. It was concluded that it is important to have a flexible system boundary and a genuine knowledge of the system studied along with close contact with the actors involved. In paper III, the actors' views are discussed together with the most important factors to enable increased integration and exchange to take place. The greatest barriers found were lack of knowledge and resources, attitudes, time frames, development consent, and lack of continuity and local power for some companies. One conclusion is that companies with integration as their business concept can be key actors when developing more integrated networks.

I was responsible for the major part of case study work, and I also wrote the papers. Mats Eklund and Mats Söderström assisted during the case studies and contributed to the planning of the study and the analysis.

\section{Paper IV}

In the study presented in papers II-III, we found that a reasonable number of exchanges could be found even in such a small municipality as Kisa. For that study I had also made a literature review where I found some literature questioning the originality of Kalundborg. These factors led me to consider the possibility to find existing examples of integration in the forest industry, using the industrial symbiosis approach. The study was conducted in cooperation with Kent Peterson who wrote a Master of Science thesis on the subject, while I wrote the paper. In paper IV, we made an inventory of the existing exchanges of material and energy in the Swedish forest industry. We found 15 networks that could be argued to fit our definition of integration, and the definition of by-product exchange networks found in literature. 
I provided the idea, background and scope of the study. Kenth Petersson carried out the survey, and visited the locations where the case studies were performed. I, in the role of one of his supervisors, assisted him in his work and helped him with analysis and interpretation. I did some additional analysis required for the writing of a scientific paper, visited one of the locations and also wrote the paper.

\section{Paper V}

During the case studies for the first papers, some conclusions were drawn about the benefits of the industrial symbiosis initiatives; however, no attempts had been made to evaluate them quantitatively. Few attempts have been made in literature to quantify IS and none of the methods used in the existing studies seemed suitable for my research questions. I wanted to use some kind of model to be able to compare directly the effects of integration, for various configurations and boundary conditions, and my co-supervisor Magnus Karlsson, who has experience of working with the computer program MIND aided me in the evaluation studies. I provided the idea and background for the study and contributed with input data. Magnus Karlsson built the models. Together we discussed and decided on boundaries, assumptions and scope and we analysed the results and wrote the paper together. In paper $\mathrm{V}$ a model including a pulp mill, a sawmill, a district heating network and a biofuel upgrading plant was used to demonstrate how the MIND method can be used to evaluate industrial symbiosis in the forest industry. The results of this study showed that there are financial benefits to industrial symbiosis compared to the same system operated in stand-alone mode, and that the industrial symbiosis configuration generates a more stable system. However, the benefits have to be evaluated from case to case since it is hard to generalize the results from a case study.

\section{Paper VI}

Since the overall aim of industrial ecology, and of my research, is sustainable development and a concern for the environment, the natural follow-up question to paper $\mathrm{V}$ was if it is possible to evaluate the assumed environmental benefits of industrial symbiosis. In paper VI we discuss some of the difficulties regarding environmental assessment. We also used the MIND 
method to compare the $\mathrm{CO}_{2}$ emissions from the same system that was presented in paper $\mathrm{V}$ using different sets of boundary conditions. The results showed that there are some benefits to the industrial symbiosis configuration compared to stand alone operation; however, we stress the importance of the assumptions made demonstrating large variations in the results for the different boundary conditions. I provided the idea, literature review and background for the study, contributed with input data and wrote most of the paper. Magnus Karlsson did most of the modelling work, although I assisted. Together we discussed and decided on boundaries, assumptions and scope and analysed the results. 


\section{SCIENTIFIC CONTEXT}

As with any interdisciplinary research project or system study, this work is related to several research disciplines. This chapter presents some related research from IS and other research fields which are related and used in this thesis. These different disciplines are also interrelated and sometimes overlap. Naturally, the list is not complete and there may be other subjects and disciplines related to IS. It should also be pointed out that only the parts of each discipline which are of interest to this thesis are presented; they are all vast research areas.

\subsection{Industrial ecology and industrial symbiosis}

Industrial ecology (IE) is an attempt to face the problems of industrial activity related to resource depletion, waste generation and pollution, using a systems view and closing material and energy cycles. Graedel and Allenby (2003) summarize the essence of industrial ecology (p. 18):

Industrial ecology is the means by which bumanity can deliberately and rationally approach and maintain sustainability, given continued economic, cultural, and technological evolution. The concept requires that an industrial system be viewed not in isolation from its surrounding systems, but in concert with them. It is a systems view in which one seeks to optimize the total materials cycle from virgin material, to finished material, to component, to product, to obsolete product, and to ultimate disposal. Factors to be optimized include resources, energy, and capital.

Industrial ecology can occur at three different levels (Figure 1). The inter-firm level can be divided into industrial symbiosis, product life cycles and industrial 
sector initiatives (Chertow, 2000). The research in this thesis is mainly conducted at the inter-firm level, within the industrial symbiosis context.

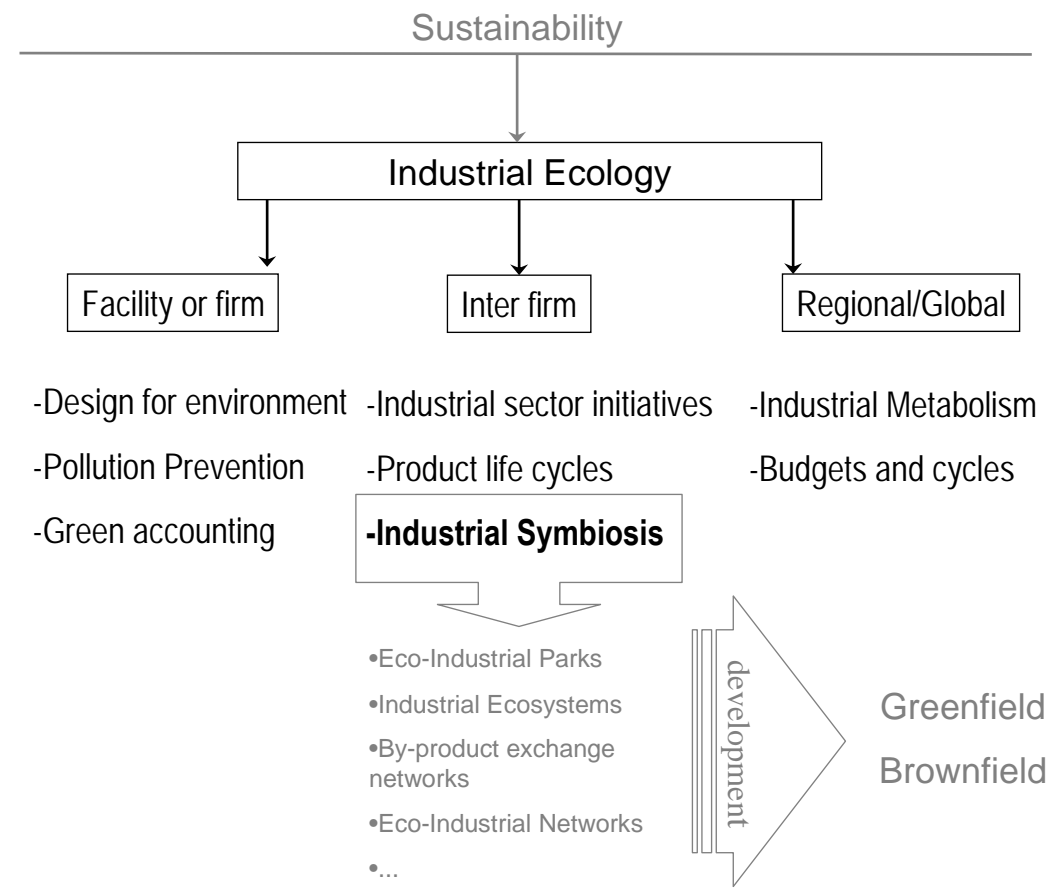

Figure 1. Context and definitions of industrial symbiosis (adapted from Chertow 2000).

\subsubsection{History}

The concept of industrial ecology emerged in the early 1990s, after an article by Frosch and Gallopoulos in Scientific American in 1989. However, even if Frosch and Gallopoulos managed to draw attention to the concept of IE, the idea was not new. The ideas behind it can be traced back as far as the 1950s and Erkman (1997) states that the industrial ecology concept was in its very early stages of development in the mid-1970s. Desrochers (2002a) investigated industrial recycling linkages and concluded that industrial symbiosis is not a break with past practices, but rather a widespread phenomenon that has been neglected by contemporary researchers. Drawing on historical documents from 1835-1928, all containing examples of by-product reuse in industry, 
Desrochers suggests that resource recovery is historically both a known and an understood concept:

Despite widely shared beliefs among contemporary experts on sustainable development that traditional economic development was characterized by a linear 'extract-anddump' model, much historical evidence illustrates that this was not the case. On the contrary, 'closed loops' seem to have spontaneously emerged wherever people were free to create the most value out of given inputs, especially in diverse cities. (p. 60)

Desrochers concludes that 'Promoting resource recovery where economically feasible and environmentally sound is simple common sense.' (p. 63)

\subsubsection{Definitions}

According to industrial symbiosis, actors could be organized into networks with integrated material and energy flows. Through increased recycling the systems could be more effective and decrease the use of resources and the discharge of pollutants. Figure 2 shows an example of increased recycling of materials and energy in industry. This way, so called industrial ecosystems can develop, with natural ecosystems as a model, where material and energy savings are important and where the material flows are mainly circular through the reuse of waste in new products (e.g. Erkman, 1997; Ayres and Ayres, 2002; Harper and Graedel, 2004).

Defining such a broad concept as industrial symbiosis is no easy task. Numerous definitions and typologies have been proposed. Chertow (2000) reviewed some of the literature in the field and stated that:

The part of industrial ecology known as industrial symbiosis engages traditionally separate entities in a collective approach to competitive advantage involving physical exchanges of materials, energy, water and by-products. The keys to industrial symbiosis are collaboration and the synergistic possibilities offered by geographic proximity. Eco-industrial parks are examined as concrete realizations of the industrial symbiosis concept. 

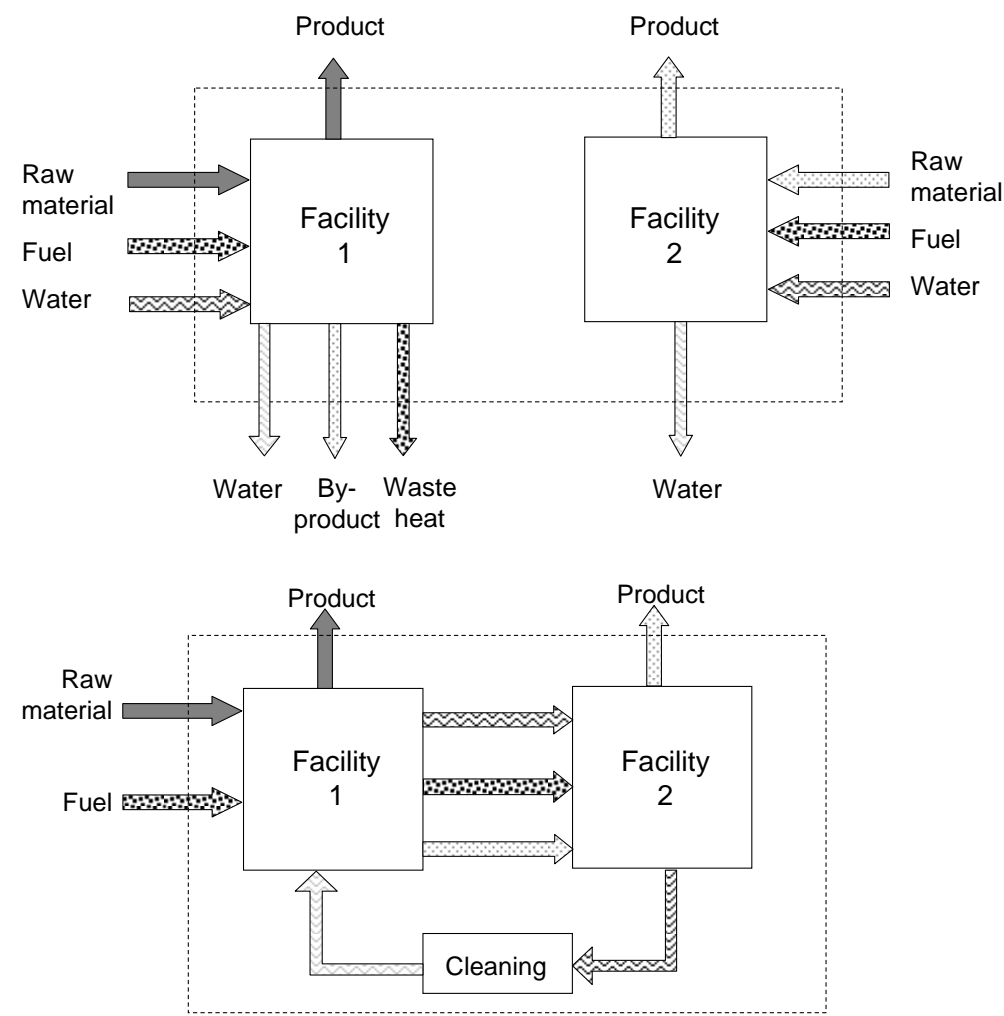

Figure 2. Simplified example of increased recycling of energy and materials.

In the Eco-industrial Park Handbook (Lowe, 2001), it is argued that the term Eco-Industrial Park (EIP) has been used in a relatively loose fashion and that a real EIP should be more than:

1. A single by-product exchange pattern or network of exchanges;

2. A recycling business cluster;

3. A collection of environmental technology companies;

4. A collection of companies making "green" products;

5. An industrial park designed around a single environmental theme (e.g. a solar energy driven park);

6. A park with environmentally friendly infrastructure or construction; or

7. A mixed-use development (industrial, commercial, and residential) 
To try to clarify the terms, Lowe distinguishes between three basic categories of eco-industrial projects:

- Eco-industrial park or estate (EIP) - an industrial park developed and managed as a real estate development enterprise and seeking high environmental, economic, and social benefits as well as business excellence.

- By-product exchange (BPX) - a set of companies seeking to utilize each other's by-products (energy, water, and materials) rather than disposing of them as waste.

- Eco-Industrial network (EIN) - a set of companies collaborating to improve their environmental, social and economic performance in a region.

Lowe's definition of an EIP is thus relatively strict and focused on management and development. Not even the leading example of industrial symbiosis, Kalundborg, can be defined as an EIP, according to Lowe, but should rather be regarded as a regional BPX.

A different typology was drawn up by Chertow (Chertow, 1999b; 2000; Ehrenfeldt and Chertow, 2002) who discussed five different types of exchanges: Type 1) through waste exchanges Type 2) within a facility, firm, or organization Type 3) among firms co-located in a defined Eco-Industrial Park Type 4) among local firms that are not co-located Type 5) among firms organized "virtually" across a broader region.

Chertow argues that types 3-5 can readily be identified as industrial symbiosis. The definition of EIP in this typology (Type 3) is somewhat less strict, and more focused on the physical flows of energy and material than Lowe's definition. Although Chertow (2002) suggests that the organizations “...can go further to share information and services such as obtaining permits, transport and marketing", this does not seem to be a demand. In a more recent paper, Chertow (2007) suggests a "3-2 heuristic", meaning at least three different entities exchanging at least two different resources, to distinguish industrial symbiosis from linear one-way exchanges. 
For all types of industrial symbiosis initiatives industrial ecologists usually distinguish between greenfield development, meaning the development of a new park or network, and brownfield redevelopment, which refers to the restructuring of an existing park (e.g. Lambert and Boons, 2002). Most existing examples of industrial symbiosis are brownfield redevelopment, and the major part of these are not even deliberately planned and labelled "industrial symbiosis" but rather developed over time as separate business arrangements. In fact, although the expectations from IS were high in the 1990s and many EIP programmes were developed both in the US and in Europe, most attempts to plan new IS projects have so far met with little success (e.g. van Leuwen et al. 2003; Deutz and Gibbs, 2004; Heeres et al. 2004; Gibbs et al. 2005; Chertow, 2007).

Van Berkel (2006) argues that there is a confusion of terms between industrial symbiosis/industrial ecosystems, dealing with physical exchanges between companies, and eco-industrial development/EIPs, dealing with environmental management and planning strategies for industrial estates. Gibbs et al. (2005), on the other hand, argue that some form of waste and energy exchange must be present to earn the appellation EIP. Lately, some authors have argued that a distinction should also be made between utility sharing and by-product exchanges since each has its own unique set of drivers, challenges and benefits (e.g. van Berkel, 2006; van Beers et al. 2007).

\subsubsection{Industrial symbiosis in practice}

The most quoted example of industrial symbiosis in practice is the industrial area of Kalundborg in Denmark where a coal fired power plant, an oil refinery and a pharmaceutical industry, a plasterboard manufacturer, a soil remediation company and the municipality are the main actors (Ehrenfeld and Gertler, 1997; Côte and Cohen-Rosenthal, 1998, Esty and Porter, 1998; Hardy and Graedel, 2002; Ehrenfeld and Chertow, 2002; Brings Jacobsen, 2006; Symbiosis Institute, 2007). There are also a fish farm making use of low-grade waste heat nearby, some local farmers making use of the by-products and an inter-municipal waste handler that support the project. The waste handler is not considered a symbiosis partner since the handling of waste products is business as usual for them (Christensen, 2007). There are different opinions in 
the industrial symbiosis literature regarding the importance of Kalundborg. Some are of the opinion that it is a paradigmatic role-model for many potential and existing IS initiatives around the world, and some maintain that it is an isolated phenomenon developed by coincidence (Brings Jacobsen, 2006). The Symbiosis Institute (2007) state that Kalundborg is unique in the world today; however, many attempts are being made to introduce new EcoIndustrial Parks around the world (cf. Lowe, 2001), as well as many arguments for the existence of IS initiatives all around (e.g. Chertow, 2007). Desrochers (2002a) also questions the originality of Kalundborg suggesting that, other than the fact that the exchanges are characterized by bulky or difficult to transport by-products and that the degree of awareness of these linkages is greater, Kalundborg is similar to many other cases of inter-firm recycling linkages.

There are also other well-documented examples of operational IS-networks in the world (for a review, see e.g. van Berkel 2006 and Onita 2006), such as those in Styria, Austria (Schwarz and Steiniger, 1997), in Landskrona, Sweden (Mirata and Emtairah, 2005, Mirata 2005), in Jyväskylä, Finland (Korhonen et al. 1999; Korhonen, 2001a; 2001b), and Kwinana and Gladstone, Australia (van Beers et al. 2007; van Berkel and Bossilkov, 2004). What they have accomplished in Kalundborg that is somewhat spectacular is that they have managed to market a rather heavy, fossil fuel based industrial area as having an environmental profile ${ }^{1}$. Indeed, the Kalundborg industrial symbiosis has sometimes been criticized since it is based on fossil fuels and materials, and some authors have emphasized the importance of switching to renewable resources (O’Rourke et al. 1996).

\subsubsection{Development and organization}

Very few attempts have been made to study the human dimensions of industrial ecology, and there is therefore a need for studies that consider sociological, cultural and organizational issues (O’Rourke et al. 1996; Côté and Cohen-Rosenthal, 1998; Baas, 1998; Cohen-Rosenthal, 2000; Ehrenfeld, 2000; Korhonen, 2001b; Korhonen et al. 2004). One reason for the lack of such studies could be that there are few documented examples, and these have mainly developed due to their historical pathway, driven by economic 
objectives, and not as a result of a conscious strategy, including the leadexample of Kalundborg (e.g. Lowe, 1997; Ehrenfeld and Chertow, 2002; Korhonen et al. 2002; Desrochers, 2004). In fact, in Kalundborg they refer to the symbiosis as a 'non-project made by a non-organization' (Christensen, 2007). This has led some authors to suggest that the industrial ecosystems should be self-organized, whereas others are of the opinion that the systems should be planned from scratch, sometimes using computer models (cf. Desrochers, 2004; van Leeuwen et al. 2003; Korhonen et al. 2002; CohenRosenthal, 2000). Some authors also argue that the fact that it may be impossible to plan local industrial ecosystems rationally does not mean that their evolution cannot be facilitated by different kinds of support (e.g. von Malmborg, 2004).

Ehrenfeld and Chertow (2002) studied the development of Kalundborg. They concluded that an atmosphere of trust existed in Kalundborg even in the absence of specific exchanges between firms. They also suggest that the regulatory system in Denmark is more consultative, open and flexible than for example in the US, which has encouraged the evolution of Kalundborg. One reason for Kalundborg's success, according to Ehrenfeld and Chertow, is that it is a dynamic and adaptive system, which prevents the technological lock-in and unhealthy mutual dependencies sometimes discussed in the industrial ecology literature. Christensen (2007) emphasizes the importance of human relationships, stating that the most important thing for the success of Kalundborg is that communication was good between the companies. This was due to the fact that the community is small and the managers were already acquainted; also, the management style is open in Scandinavian countries. One other important factor for the development of Kalundborg was the steam delivery from the power plant. This was one of the first projects in Kalundborg, and since it involved four of the six partners it paved the way for further industrial symbiosis projects since it was very successful and gave the companies involved a positive view of co-operation (Christensen 2007).

Heeres et al. (2004) compared the progress of some projects in the US with some in the Netherlands. They concluded that the projects in the Netherlands 
were more successful than the US projects. They suggest that this could be attributed to the fact that the US projects were initiated by local and regional governments, which killed companies' interest from the start, whereas the projects in the Netherlands were initiated by the companies with the support of local and regional authorities. Heeres et al. also state that the establishment of exchange relationships can run into five different types of barriers: technical, economic, informational, organizational and regulatory/legal. The most important barrier mentioned is lack of company interest, which they conclude is 'deadly' to the project.

Sterr and Ott (2004) argue that for eco-industrial parks to spread, the concept has to take a more realistic course, focusing on developing the existing potential rather than plan idealistic visions, such as greenfield development. In their opinion, co-location of industrial plants that fit together is a relatively rare phenomenon. Other authors have also come to recognize the importance of networks where some type of material or energy exchange already exists and argue that they can be used to springboard other exchanges and can thus be viewed as the initial stage of broader industrial ecology (e.g. Chertow, 1999b; 2007).

\subsubsection{Industrial symbiosis in the forest industry}

Previous studies of industrial symbiosis in the forest industry include some examples from Finland (Korhonen, 2001a; 2001b; Korhonen et al. 2001; Korhonen et al. 2002; Snäkin, 2003). Korhonen et al. (2001) developed a theoretical model of the flow of matter, nutrients, energy and carbon in a natural forest ecosystem and applied this model to the national forest industry in Finland. They argue that the national forest industry could serve as an example of an industrial ecosystem. The industrial actors have, according to Korhonen et al. developed material cycles and more efficient ways of using the raw material. It is also seen that cutting is lower than growth, which means that the forests have a capacity to decrease the amount of $\mathrm{CO}_{2}$ in the atmosphere. Korhonen et al. briefly discuss the implementation and argue that since the development of industrial ecosystems is often dependent on various situational factors, much more empirical data is needed before detailed design or policy principles can be drawn up. 
Korhonen (2001a) investigated two examples of regional industrial ecosystems in Finland. In one system based on co-operation between heavy industrial plants, the actors include forestry companies, a sawmill, a pulp mill, a paper mill and a forest industry power plant. Wood waste from sawmills is used in pulp production and for energy uses. In the power plant, black liquor and wood wastes are used. Pulp mills provide waste heat, which can help to fulfil the heating requirement in paper production. Korhonen states that, because of recycling of matter, nutrients and carbon as well as waste energy utilization, significant amounts of virgin resources can be saved. Less than $2 \%$ of the harvested round-wood ends up as waste and is not used. The Jyväskylä industrial ecosystem, on the other hand, is based on the involvement of households and end-consumers including a CHP-plant, a paper mill, a horticultural centre, a plywood mill and the local municipality. Korhonen presents a vision of a regional industrial ecosystem with integrated production and end-consumption systems based on these two examples. According to the study, there is great potential in Finland in this respect, since 11 forest industry combines exist and many of these are located near cities, towns or residential concentrations. Korhonen argues that the diversity of actors can lead to complications and that the interdependency leading to unhealthy dependencies could be a problem. However, the study lacks empirical data about the non-technical issues.

\subsubsection{Integrated biofuel upgrading}

The part of this research presented in paper I concerns integrated biofuel upgrading. This could be seen as an initial stage of industrial symbiosis, although previous research in this field has been conducted under other names, such as biofuel combines. In the early 1990s a study was made of the conditions for producing and upgrading biofuel in the forest industry (Magnusson, 1991). At that time, the sawmills were finding it difficult to dispose of biofuel by-products. In the pulp and paper industry, integrated biofuel upgrading was considered worth taking a look at. However, it was not thought likely that the pulp and paper mills would invest in a production facility for biofuel since their core business area was pulp and paper production. If the pulp and paper mills increased the availability of excess heat 
through energy efficiency, it would be a more interesting prospect according to Magnusson.

Earlier studies of existing Swedish pellet production plants combined with industry have covered a heat and power plant in Skelleftea that is integrated with a pellet factory (Atterhem, 2001; Pettersson, 2002; Wahlund et al. 2002; Wahlund, 2003). Wahlund (Wahlund et al. 2002; Wahlund, 2003) investigated costs, environmental effects and non-technical factors of the biofuel combine in Skellefteå. He concluded that the system provides a good opportunity for increased biomass utilization and that a substantial decrease in emissions of $\mathrm{CO}_{2}$ can be achieved. Wahlund also found that the main criterion behind the investment was a shared view of the potential profitability. He also concluded that another important factor for the realization of the biofuel combine was that the municipality, as owner, had taken a position of active responsibility for the whole region and its development. Environmental factors did not seem important for the realization; this leads Wahlund to the conclusion that companies operating in a local context have limited interest in global environmental issues. Therefore, he argues, it is the state or government that has to form an institutional framework to induce global environmentally friendly investments on the local level.

Bioenergy combines have also been studied by, for example, Johansson and Westerlund (1999) who studied an open absorption system for biofuel drying installed at a sawmill, Vidlund (2004) who studied biofuel upgrading in the forest industry, and Andersson (2007) who studied biorefineries.

\subsubsection{Evaluation of industrial symbiosis}

The by-product synergies linked to industrial symbiosis are often assumed to provide environmental benefits, contributing to the overall goal of sustainability that industrial ecology aims to achieve. Also, financial benefits are assumed to be achieved, describing IS as a "win-win" situation. However, the lack of studies in the field confirming this theory is obvious. Very few attempts have been made to quantify these benefits, either theoretically or through case studies, and many of the existing studies often present neither assumptions nor methods for calculations. 
Not even in Kalundborg, the most documented example of industrial symbiosis in literature, has a thorough evaluation been made. Brings Jacobsen (2006) made a quantitative evaluation of parts of the Kalundborg industrial symbiosis system, but limited to a single resource - the water exchanges, and found some support for the theories of economic motivation as well as some environmental benefits. Some estimations of savings in water, oil equivalents and natural gypsum have also been made for the Kalundborg IS network (Symbiosis institute, 2007; Christensen, 2007) but these are typically presented without accounting for assumptions or the method of calculations. Singh et al. (2006) performed an LCA-type environmental impact assessment for different design schemes of an industrial ecosystem using a software tool. However, the different design schemes used include different plants and processes as well as new products, which makes it difficult to see to what extent the environmental benefits can be attributed to industrial symbiosis in particular. Chertow and Lombardi (2005) made an assessment of a proposed industrial symbiosis network in Puerto Rico, similar to the Kalundborg complex, and found some economic, regulatory and environmental benefits for the separate companies involved.

The industrial ecology tool-box borrows from all the contributing disciplines and includes many different approaches such as case studies, material and energy flow analyses, life cycle assessment and design for environment (van Berkel et al. 1997; Graedel and Allenby, 2003). However, when evaluating effects of real life industrial symbiosis systems some difficulties have to be overcome. One such issue is that it is hard to determine which of the savings come from the actual integration of the company into the industrial symbiosis and which measures would have been taken anyway, or that could be attributed to other means for cleaner production. Also, since real-life experiments on large systems, such as industrial parks and networks, are challenging due to complex structure and high costs, evaluation can only be made on the basis of historical data. It is also difficult to decide to which reference system the IS should be compared: to a similar stand-alone system, to the original industrial park, which may not even contain the same companies as the present system, or to the most likely alternative develop- 
ment (c.f. Brings Jacobsen, 2006)? These concerns along with the limited number of examples that exist make the results from such evaluations hard to generalize and to use as policy implication for new, potential industrial symbioses.

One way to overcome the generalization problem is to use models as decision support, both for general statements and for evaluation of specific systems. Traditionally, industrial ecologists use material and energy balances to plan and evaluate industrial ecosystems. However, when the systems become more complex they can be difficult to handle without using computer modelling tools that facilitate the evaluation of material and energy flows. Diwekar (2005) suggests that since decision making is driven by different objectives such as costs, environmental impact etc., modelling that includes uncertainties in predicting these various objectives is required. Process analysis and CPS (Chemical Process Simulation), originally designed to analyse industrial unit operations, has been suggested as a tool to analyse more complex industrial ecosystems by several authors (Diwekar, 2005; Diwekar and Small, 2002; Casavant and Côté, 2004). Casavant and Côté suggest that CPS can be used to quantitatively evaluate and compare the potential financial and environmental benefits of material and energy linkages, solve design, retrofit and operational problems, identify complex and often counter-intuitive solutions and to evaluate what-if scenarios. Software tools based on the techniques from process integration using mathematical programming are also developed for site integration. Lambert and Boons (2002) found that process integration is widely applied and has great potential for industrial complexes but is a relatively new subject, with marginal potential, for mixed industrial parks.

Concerning environmental assessment, there are also many general difficulties, discussed in literature, such as issues of boundaries and time perspectives, allocation problems, lack of knowledge regarding how certain emissions affect the environment, data gaps and valuation and weighting of different environmental problems (e.g. Ammenberg, 2003; Finnveden, 2000; Russel et al. 2005) which affect IS as well. By using indicators, some of these problems might be overcome (e.g. Tyteca et al. 2002, Svensson et al. 2006), and this is a method often used in energy systems research, using $\mathrm{CO}_{2}$ 
emissions as the only measure of environmental pressure. However, concerns such as system boundaries, emissions accounting, allocation etc. may remain, depending on the type of indicator. It is also important to realize that indicators often reflect the environmental issues in focus at the time, and that their usefulness might depend on the type of process or product studied and on the system they operate in (Svensson et al. 2006).

\subsection{Cluster theory}

The problem of competition between co-located industries in the same sector, as mentioned in the industrial ecology literature (e.g. Boons and Baas, 1997), is connected to the research field of cluster theory and industrial network theory. Competition could be diminished if a larger sector, such as the forest industry, is considered, where the companies could use each others' products or by-products as raw material (e.g. sawmill - pulp mill - paper mill - paper processing industry). Moreover, if companies with similar products but different niches are considered there would be no direct competition; instead, they could benefit from each others' competence and shared network of suppliers and service companies (NUTEK, 2001; National Govenors Association, 2002). These types of clusters can lead to business, marketing and economic advantages for the companies.

Cluster theory, however, is seldom focused on environmental issues (NUTEK 2001; National Govenors Association, 2002; Esty and Porter, 1998) although environmental policies can give the companies involved a competitive edge. Cluster and network theory and industrial ecology have a lot in common; however, they rarely interact:

Industrial network and industrial ecology theory have missed each other like two ships in the night, yet they sail the same waters. (Cohen-Rosenthal, 2000, p. 257).

A recent exception is Deutz and Gibbs (2007) who use an empirical focus on eco-industrial developments in the USA to postulate that IS can be viewed as a distinct cluster concept. The concepts of industrial ecology and cluster and network theories have a lot to learn from each other since networks and cooperation are cornerstones of industrial ecology (Ehrenfeld, 2000). The 
Swedish forest industry as a whole has been identified as a cluster of great importance. Co-operation within the cluster and with outside partners generates employment, know-how and competence throughout the entire cluster (Swedish Forest Industries Federation, 2004). Cluster theory is therefore relevant to the research questions concerning organization and development in this thesis.

\subsection{Inter-organizational relationships}

The human dimensions of industrial symbiosis studied in this thesis concern different forms of inter-organizational relationships. Both industrial symbiosis and cluster theory encompass different forms of inter-organizational relationships; Korhonen et al. (2004) link industrial ecology to management and policy issues, suggesting that the systems and network philosophy of IE can be coupled with inter-organizational management studies. Previous research in the field of inter-organizational relationships has focused on how to help firms create value by combining resources, sharing knowledge, shortening time to market, and gaining access to foreign markets (Barringer and Harrison, 2000). Barringer and Harrison found that inter-organizational relationships are difficult to handle and even if they can be theoretically advantageous, many fail as a result of the complexities involved and the need to bring together the corporate cultures of two or more firms. When companies choose to be part of inter-organizational co-operations it is normally due to a variety of interacting causes. Alter and Hage (1993) mention willingness to co-operate, need for expertise and need for financial resources and shared risk as crucial factors. According to Alter and Hage, the most important factor is the willingness to co-operate; without that the cooperation will fail.

There are several potential advantages of co-operation: gain access to a particular resource, economies of scale, risk and cost sharing, gain access to a foreign market, product and/or service development, learning, speed to market, flexibility, collective lobbying, neutralizing or blocking competitors (Barringer and Harrison, 2000). According to the same authors, potential disadvantages can be: loss of proprietary information, management complexities, financial and organizational risks, risk of becoming dependent on a 
partner, partial loss of decision autonomy, partners' "cultures" may clash, loss of organizational flexibility, antitrust implications.

\subsection{Investments - internal integration of processes}

In some cases, the integration projects, or parts thereof, consist of exchanges between different facilities or plants which are located at the same site and belong to the same company. The necessary investments to realize such projects can be seen as energy, environmental or strategic investments from the company's perspective.

The advantage of this way of organizing integration is that some problems that are usually connected with co-operation between industries can be avoided. These can include, for example, problems with trust, price setting of waste heat and by-products, forming of contracts, conflicts over goals and methods, etc (Möllersten and Westermark, 2001; Alter and Hage, 1993). However, other obstacles may be more problematic with this type of organization. More focus may be on profitability, and the short payback times required in the forest industry can therefore be an obstacle. The tendency for an industry to focus on its core competence (Sandberg and Söderström, 2003; Möllersten and Sandberg, 2004; Laestadius, 1996) may also act as a barrier to increased integration.

An important factor for a company when investing in a new process is risk. Previous studies of the pulp and paper industry (Laestadius, 1996; 2000; 1998) have indicated that the companies are risk-averse and that old industries often "fail to grasp the leadership in new technologies". According to Laestadius (1996), this is due to the fact that the companies often deal with very large investments where they cannot afford to fail. This rationally motivated caution then spreads to other types of investments as well. The pattern can be assumed to be valid for both the pulp industry and the paper industry, and might be partly true for sawmills, since they are part of the forest industry as well and are often owned by the same companies or are parts of the same group of companies. 


\section{OBJECTIVE AND SCOPE OF THIS WORK}

In this chapter, the objective, research questions, definitions and limitations are presented.

\subsection{Objective and research questions}

The objective of this work is to apply the framework of IS to the Swedish forest industry. Through the empirical experience gained, knowledge is produced which can be used for critical analysis and for further conceptual development of the IS framework. It can also be used to evaluate how the industrial symbiosis approach can contribute to resource efficiency in the forest industry.

The research can be divided into three different areas: occurrence, development and evaluation. Drawing on the objective and the available literature, three main research questions emerged during the process of the work, one concerning each research area:

Occurrence Can industrial ecosystems or other examples of integration be found in the Swedish forest industry using the industrial symbiosis framework?

Development How have the systems evolved, how can the existing systems be further developed and how can the knowledge be implemented in new systems? 
Evaluation How can the success of industrial ecosystems or other examples of integration be evaluated from an economic and environmental point of view?

\section{Definitions and limitations}

The main driving force in this work has been concern for the environment and IS aims to decrease the environmental pressure of industry by promoting the 'win-win' of eco-efficiency which is about creating more value with less impact, meaning that environmental savings (e.g. through reducing material and energy use, increasing recycling and using renewable resources) can also bring cost savings (WBCSD, 2000). Therefore, in this thesis, 'efficiency' is essentially defined as eco-efficiency unless it is directly stated that an environmental, technical or financial viewpoint is being taken.

The term 'integration' is used throughout the thesis, together with 'industrial symbiosis' and 'industrial ecosystems'. Integration is used mainly on a macro level to denote integration, in the form of energy and material exchanges, between different entities. Industrial ecosystems are concrete realizations of the ideas of IS, i.e. integration of several units and/or several streams. Within industrial ecology research there are different opinions concerning which constellations to include under the banner of industrial symbiosis. In the industrial symbiosis complex in Kalundborg for example, only material and energy exchanges between different legal entities are considered (Christensen, 2007). Indeed, when it comes to implementation of new industrial ecosystems, the ownership of the companies, negotiations and the relationship between different entities are crucial. However, from a technical point of view it does not really matter to efficiency and environmental impact who owns the production units. Therefore, in this work, integration is also used to denote co-production of products normally produced in stand-alone production, even if the same company owns both facilities. However, the term integration is assumed to be more than heat exchange between streams within one industry or conventional use of by-products and raw materials. Traditional supply chain exchanges are therefore not considered to be integration. There is no distinction, however, between utility synergies and by-product synergies since this distinction is difficult to make in the forest industry where some by- 
products are also part of the utility system (for example sawdust and wood chips which might be turned into new products, used as raw material in pulp production or as fuel for heat production). It is acknowledged, however, that the above definitions are conditioned by the time in which the system operates since new by-product synergies may be considered as traditional supply synergies once matured.

This research mainly concerns the production phase and whether production can be achieved with less environmental pressure using the framework of IS than in traditional, stand-alone production. Although it is acknowledged that many other factors play important roles for the environmental pressure of the forest industry from a life cycle perspective, such as forestry, end use of the products, alternative products and uses of raw material etc, the analysis of these does not lie within the scope of this thesis. Also, the focus lies on the co-operations between different entities regarding energy and material exchanges, and to some extent transportation and other factors that fit into the framework of IS. Other means for cleaner production, although these may be equally, or even more, important are not considered specifically.

Concepts such as sustainability, reduced environmental impact or ecoefficiency upon which IE and IS rely are multi-faceted and difficult to define properly and objectively. In this work, it is mainly the environmental aspects of sustainability that are considered although the importance of social factors and economic aspects is acknowledged. The environmental dimension is considered rather through qualitative valuing of generally accepted factors, for example that a reduction in emissions, waste material dumped, virgin material used and transportation is desirable. In the quantitative assessment only $\mathrm{CO}_{2}$ emissions are considered. This is a gross simplification, but it represents an important environmental problem today and the study is used mainly to illustrate the complexness of environmental assessment and to evaluate the use of the MIND method for such purposes. A complete environmental assessment regarding all possible impacts from the forest industry on nature lies outside the scope of this thesis. 


\section{METHODOLOGY}

Due to the interdisciplinary character of this study, several different methods have been used. This chapter describes the methods and explains how they are connected and used.

\subsection{Approaches}

The following approaches were used to address the research questions:

1) Identifying and describing different examples of industrial symbiosis in the forest industry in Sweden.

2) Analysing how some specific cases have evolved and the human dimensions of such IS projects.

3) Attempting to further develop a local industrial ecosystem in the forest industry, and evaluating that approach

4) Using an optimization model to evaluate the economical and environmental benefits of industrial ecosystems.

A summary of the contribution of the different papers to the thesis is given in Table 1.

Table 1. Research contribution of the papers.

\begin{tabular}{llll}
\hline Paper & Approach & Method & Contribution to research area \\
\hline I & 2 & Case studies & Development \\
II & 3 & Case study & Development \\
III & 2 & Case study & Development \\
IV & 1 & Inventory / Case studies & Occurrence \\
V & 4 & MIND method & Evaluation \\
VI & 4 & MIND method & Evaluation \\
\hline
\end{tabular}




\section{2 Case studies}

Given the nature of the research questions, one of the methods chosen in this thesis work is a form of case study which addresses the technical parts of the systems as well as the social parts. It is equally important to understand and address the social aspects of the systems as the technical aspects. I am not a social scientist; I have therefore tried to adopt some basic knowledge regarding theories and methods from social science disciplines along the way using books and courses and I have had to rely on the help offered by colleagues and supervisors in that area. Still, there might be limitations in my knowledge and experience of setting up a study involving a social science dimension. The advantage, on the other hand, is a good technical knowledge of the system which could mean an opportunity for better communication with representatives of the industries and a better understanding of the processes. I can not judge whether the case studies would have been 'better' had a social scientist conducted them - I can only assume they would have been different and focused on other research questions.

The case study methodology is appropriate when "how" and "why" questions are asked, and when the circumstances of the process cannot be controlled (Yin, 1994). No statistical results can be obtained from case studies nor can the results be directly generalized to other cases outside of the study.

Nevertheless, case studies with strong empirical influences can contribute to the research in an interdisciplinary study in several different ways:

- They can contribute to empirical tests of general ideas and help support or disprove an existing theory by comparing the results to theories and previous research.

- By observation of facts and situations not included in existing theories they can contribute to the development of new theories and models.

- Case studies provide an opportunity to systematically examine qualitative data that is not so easily aggregated. Case studies can thus contribute to knowledge about conditions that can only be described in qualitative terms. 
In order to assure validity and credibility, different sources of information are used, such as interviews, direct observation at the sites, websites, newspaper articles, etc. The informants from the companies have also been able to study and comment on drafts of the studies in order to increase the validity. One problem in this type of case study is that important information is often confidential.

The interviews contributing to the non-technical questions are of two different kinds:

- In papers I-III, separate interviews were conducted with one or, on one occasion, two people at a time. At each site, at least one person with knowledge about the company's strategies and views on possible integration was chosen as informant. These informants were interviewed in a conversational, open-ended manner at the sites.

- In paper III, a group discussion influenced by the research on focus groups (Wibeck, 2000) was held. The actors involved in the project were given the opportunity to comment on the different improvements suggested. Representatives of all the main actors except one took part in this discussion.

The technical parts of the case studies consist of mapping energy and material flows, and existing material and energy exchanges. The potential for energy savings is based on mass and heat balances over the studied systems. The flows are analysed for possible exchanges and potential improvements, considering factors such as quantity, quality, continuity and variations over time.

The technical study of the systems and the non-technical questions complement each other in different ways. The technical study, with suggestions for improvements, was an important part of the group discussions with the actors in paper III, and was part of the interviews on obstacles and success factors in paper I and III. The informants also commented on the technical studies, correcting and adding to the information where necessary. They also provided valuable information on other aspects of the integration projects than what 
can be found in an energy and material flow analysis, helping create a more complete picture of the systems.

\subsection{Inventory of industrial symbiosis in the Swedish forest industry}

In paper IV, an inventory was made of existing material and energy exchanges in the forest industry. First, a list of all existing pulp and paper mills, sawmills with an annual production of $>100,000 \mathrm{~m}^{3}$ and biofuel producers that could be identified using organizations such as the Swedish Bioenergy Association (Svebio) and the Swedish Forest Industries Federation and internet search engines was compiled. The inventory was conducted using e-mail and/or telephone to contact the companies included with questions regarding existence of material and/or energy exchanges with adjacent industries (for an example of a questionnaire, see Peterson, 2006). A thorough literature study was made to draw up the theoretical framework used to analyse the results depending on the degree of integration.

\subsection{The MIND method}

In papers V and VI, the MIND method, Method for analysis of INDustrial energy systems, is used (Nilsson, 1993; Karlsson and Sandberg, 2007). It is based on mixed integer linear programming (MILP) and has mainly been used for modelling of industrial plants and to some extent for modelling the interaction between an industry and a district heating system (e.g. Bengtsson et al. 2002; Sandberg et al. 2004) although the method is designed for general problems. Different issues may be in focus in the studies, such as the structure of the system, the influence of different boundary conditions and operating strategies. The system cost, including e.g. cost for energy and material, is usually optimized. However, it is possible to use a multi-objective approach (Sandberg and Larsson, 2004).

Using the computer program reMIND, different models are constructed, which are pictured by nodes and branches. The branches represent a flow of any kind while the nodes may represent a component, a process unit, or a complete process line. The dynamics of a model is represented by time steps, to visualize diurnal, weekly or daily variations. The length of each time step is 
adjusted accordingly and different time steps may be connected to each other through storage functions or batch functions. The model is constructed in the reMIND interface; running it generates a set of equations which are solved in an optimizer (Cplex) which minimizes the objective (the system cost, normally). A screen dump of the graphical interface is shown in Figure 3 that is an illustration of one of the models used in papers V-VI.

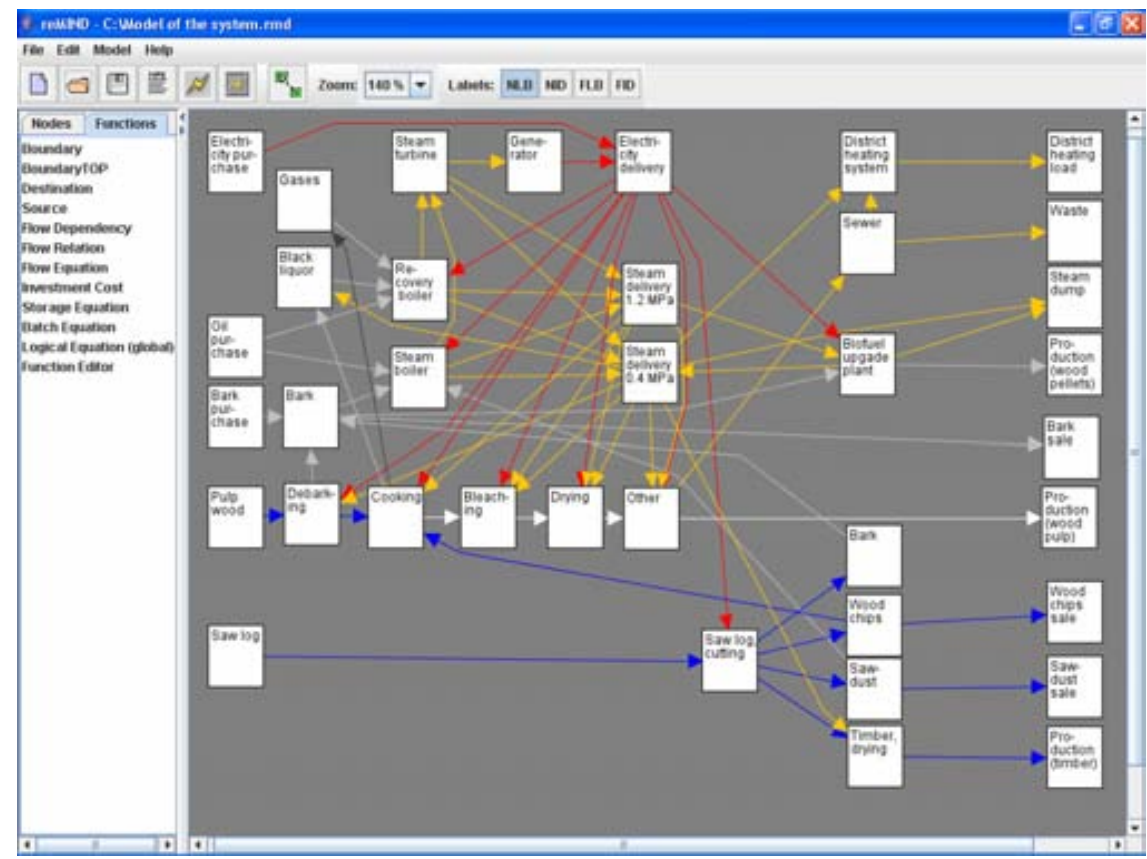

Figure 3. Screen dump from the reMIND interface, showing a simplified model of the system studied in paper V-VI. 


\section{INDUSTRIAL SYMBIOSIS IN THE SWEDISH FOREST INDUSTRY - DEVELOPMENT AND STATUS}

This chapter includes some historical perspectives, mainly based on a literature review, and some lessons learned from the case studies. The results from paper IV regarding the situation today are also presented.

\section{1 Historical background}

In Sweden, it can be argued that the basic ideas of industrial symbiosis have existed for decades in the forest industry. In Billow (1928) for example, the forest industry complex of Skoghall is described as a model plant containing almost all industrial branches of wood manufacturing (Figure 4). Furthermore, Strukturutredningen (1971) names at least five examples of such areas of "forest industry complexes" just in passing.

One factor important for localization of sawmills has been the possibility to be integrated with other forest industry, mainly pulp mills (Strukturutredningen, 1971, p. 22). A government inquiry from 1969 concluded:

A rational flow of timber presupposes that the raw material is transported unsorted to a combined pulp and sawmill industry [...] which consume different dimensions of both softwood and hardwood. A united industrial system including one or more pulp industries and a number of saw mills localized on "the way in" to the pulp manufacturing should also be considered as a rational solution since the by-products from the saw mills are used in the pulp manufacturing. The systems 
must be developed considering, among other things, infrastructures, the structure of the existing sites and the localization of the wood manufacturing industry. (Strukturutredningen, 1971, p 24, my translation).

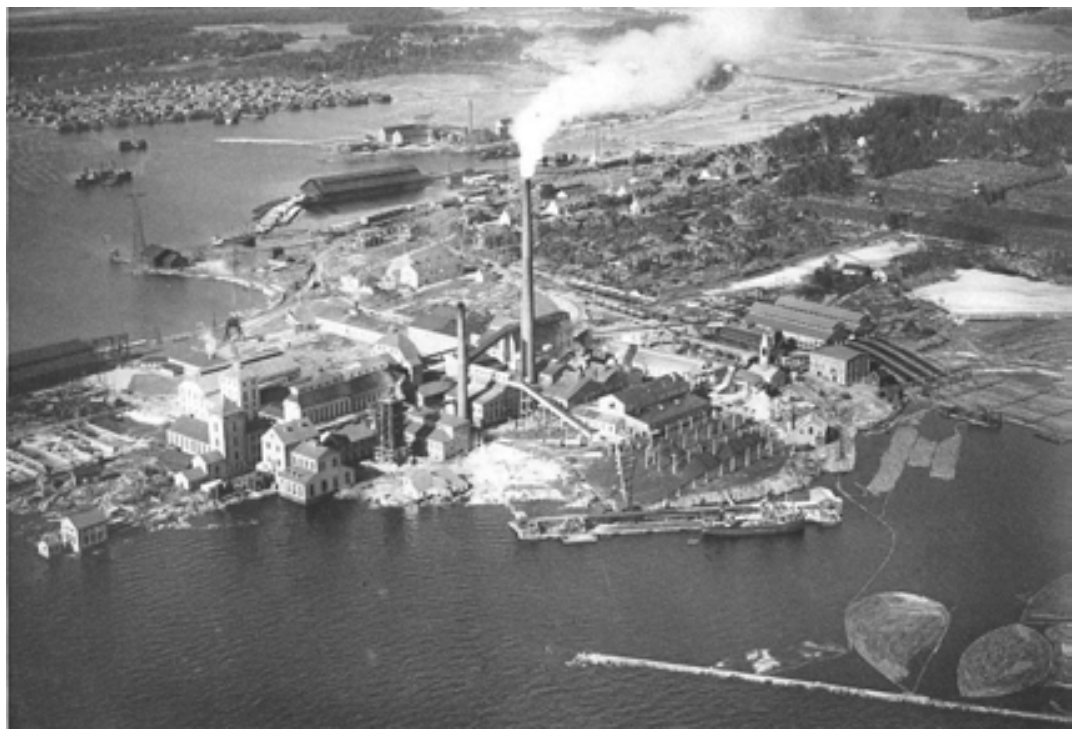

Figure 4. A picture of Skoghallsverken from Billow (1928), where the area is described as a model plant containing almost all branches of forest industries.

Also, considering the manufacturing of wood based particle board, which was a new product in the Swedish forest industry in the early 1970s, it is stated:

Particle board was manufactured in combination with other wood industry from the start. The technical integration with mainly sawmills and pulp mills $[\ldots]$ has lead to an opportunity for a highly economical use of former waste products. [...] An additional reason [for colocalization] was the access to electrical power and the possibility to use existing channels for sale and distribution of other forest industry products. (Strukturutredningen, 1971, p 140-142, my translation)

It goes on to discuss the advantages of integrated pulp and paper production, the up-grading of by-products in the pulp industry etc, constellations that are considered more or less standard procedure today, and therefore do not fit under the description of industrial symbiosis as "traditionally separate 
entities" working together. This definition might lead to a question of time frames rather than of technical solutions and environmental and economical benefits, however.

The question that arises when studying these historical examples of industrial recycling linkages is whether the only reason for the lack of literature describing this phenomenon during the 20th century, before the introduction of IE in 1989, is neglect by contemporary researchers. Desrochers (2002b) suggests that one additional reason is the progressive implementation of market distortions and regulatory barriers to resource recovery over the last century. Among the barriers mentioned are institutional barriers to resource recovery, transport cost discrimination against secondary materials, subsidies to the primary sector, and the fact that many policy makers have come to view industrial by-products as a 'nuisance to be destroyed' rather than as resources. Another problem mentioned is that industrial by-products are often regarded as hazardous waste, restricting handling and making reuse impossible or difficult. Desrochers argues that modern legislation establishes an arbitrary distinction between a useful material and waste and suggests that the solution might be to force firms to 'internalize their externalities' since it is in the nature of the market economy to close material loops if the industries are accorded the necessary freedom to develop new uses for by-products. One additional problem might be the trend during the second half of the 20th century for industry to focus on its core business, leading to outsourcing of for example energy facilities.

\subsection{The situation today}

The debate may go on regarding the historical development of industrial symbiosis. Still, the question of whether it is common practice, a forgotten approach or a new development does not influence the possibilities of industrial symbiosis to be a tool for a more efficient use of resources in industry today.

In the study presented in paper IV, it was seen that Sweden's forest industry companies co-operate extensively through material and energy exchanges today. From the high participation rate in the inventory and due to the fact 
that negotiations concerning new exchanges were initiated in several cases, it was also concluded that these questions were of interest to the companies.

To study the occurrence of industrial symbiosis in the Swedish forest industry, an inventory was made identifying a total of 152 industries, 117 of which participated in the study by means of their answers. In all, 57 of the participating industries have some kind of material or energy exchange with adjacent companies. Of these, 33 are part of BPX networks, forming 15 networks, one of which is a larger region. Apart from the companies that are part of BPX networks, 18 delivered heat to adjacent industries. Seven cases of co-operation that reduces transportation were also found (companies that sell by-products to be used as raw materials or energy sources locally).

In Table 2, the 15 networks are listed according to the number of exchanges and entities involved as well as the types of industries.

The companies in the inventory comprised 63 sawmills, 13 pulp mills, 21 paper mills, 25 integrated pulp and paper mills, and 26 bio-fuel producers. As can be seen in Table 2, 13 sawmills, five pulp mills, two paper mills, nine integrated pulp and paper mills, and six companies producing other wood based products (four of which are bio-fuel producers) are members of BPX networks. Most of the companies in the networks are forest industry companies, but one smelter, five heat plants, two recycling companies and two other processing industries can also be found.

Several of the exchanges mentioned revolve around electricity, steam, and byproducts from sawmills, such as woodchips and sawdust. Nevertheless, a few other interesting exchanges were also identified during the study, for example sludge from some of the pulp mills is used as fuel, soil fertilizer, and for covering material at landfills. 
Table 2. Description of the by-product exchange networks.

\begin{tabular}{|c|c|c|c|c|c|c|c|c|c|}
\hline Network & $\begin{array}{l}\text { Saw- } \\
\text { mill }\end{array}$ & $\begin{array}{l}\text { Pulp } \\
\text { mill }\end{array}$ & $\begin{array}{l}\text { Paper } \\
\text { mill }\end{array}$ & $\begin{array}{l}\text { Int. } \\
\text { pulp \& } \\
\text { paper }\end{array}$ & $\begin{array}{l}\text { Bio-fuel } \\
\text { or other } \\
\text { wood } \\
\text { based } \\
\text { products }\end{array}$ & $\begin{array}{l}\text { District } \\
\text { Heating }\end{array}$ & Other & $\begin{array}{l}\text { Total } \\
\text { No. of } \\
\text { Entities }\end{array}$ & $\begin{array}{l}\text { No. of } \\
\text { exchanges }\end{array}$ \\
\hline Norrsundet & 1 & 1 & & & & & & 2 & 2 \\
\hline Grums & 1 & & & 1 & 1 & & & 3 & 3 \\
\hline Iggesund & 1 & & & 1 & & 1 & & 3 & 4 \\
\hline Vargön & & & & 1 & & 1 & $1^{\mathrm{a}}$ & 3 & 3 \\
\hline Katrinefors & & & 1 & & & 1 & $1^{\mathrm{b}}$ & 3 & 3 \\
\hline Piteå & 1 & & & 1 & & 1 & & 3 & 3 \\
\hline Vilhelmina & 1 & & & & 1 & & $1^{\mathrm{b}}$ & 3 & 2 \\
\hline $\begin{array}{l}\text { Obbola- } \\
\text { Holmsund }\end{array}$ & 1 & & & 1 & & 1 & & 3 & 2 \\
\hline Värö & 1 & 1 & & & & 1 & & 3 & 3 \\
\hline Lövholmen & 1 & & & 1 & & 1 & & 3 & 2 \\
\hline Domsjö & & 1 & & & & 1 & $2^{c}$ & 4 & 7 \\
\hline Mönsterås & 1 & 1 & & & 1 & 1 & & 4 & 9 \\
\hline Rundvik & 1 & & & & 2 & 1 & $2^{\mathrm{b}}$ & 6 & 15 \\
\hline Gävle & 1 & & & 1 & & 1 & $2^{\mathrm{d}} ; 1^{\mathrm{b}}$ & 6 & 10 \\
\hline $\begin{array}{l}\text { Sundsvall- } \\
\text { Timrå }\end{array}$ & 2 & 1 & 1 & 2 & 1 & 4 & & 11 & 19 \\
\hline
\end{tabular}

\footnotetext{
${ }^{a}$ smelter

${ }^{\mathrm{b}}$ heat plant

${ }^{\mathrm{c}}$ process industries

d recycling company
}

In all but three of the fifteen networks, heat is delivered to the local community. In this study, it is not further evaluated whether the heat is waste heat or not. If it is waste heat, for example low temperature process water which is heat pumped, or steam which would otherwise have been wasted, the benefits, both economically and environmentally, are obvious. However, if additional fuel has to be used in the industry to provide heat for the municipality the benefits are dependent on what type of fuel it replaces and the efficiency in heat production compared to a traditional bio-fuel boiler for example. 
It can also be noted that a sawmill takes part in all but three of the networks and that all but two have either a pulp mill, a paper mill or an integrated pulp and paper mill. Only five of the networks have some kind of bio-fuel producer or board manufacturer, which is a little surprising since their products are based mainly on by-products from the sawmills and pulp mills, and because the situation described in the historical development (section 5.1) suggested that co-production of particle boards in the forest industry was standard practice in the 1970 s.

\subsection{Case studies}

During the work presented in this thesis, several case studies have been conducted. The technical aspects of these case studies are presented here along with brief histories of development.

\subsubsection{Mönsterås}

In Mönsterås, a chemical pulp mill, a sawmill and a pellet production facility are co-located and partly integrated. The sawmill and the pulp mill have different owners, but are part of the same group of companies (Södra). Integrated in, and owned by, the pulp mill is a pellet production plant.

The pulp mill was built in 1959, the pellet production plant in 1996 and the sawmill in 1999. The annual production capacity is 750,000 tonnes of pulp, 35,000 tonnes of pellets and $370,000 \mathrm{~m}^{3}$ of sawn wood. The pulp mill produces a total of about 1.8 TWh of biofuel annually (excess bark, wood chips and pellets) which makes it one of the largest biofuel producers in Sweden. Adjacent to the pulp mill are a port and a railway, which also facilitates transportation. The by-product exchange network is described in Figure 5. 


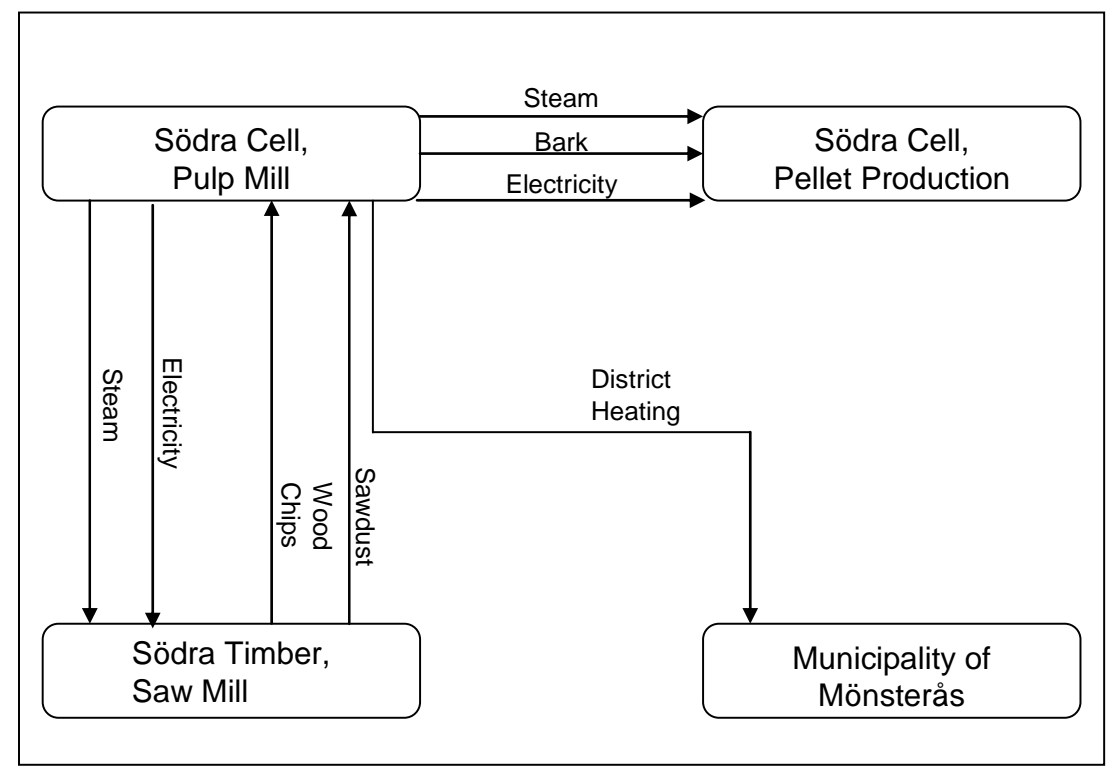

Figure 5. The integration of pulp mill, sawmill and pellet production in Mönsterås.

\section{Integration pulp mill - sawmill}

The sawmill supplies wet woodchips and sawdust to the pulp mill as raw material. The bark is sold externally since the pulp mill has no capacity to use it. The pulp mill delivers electricity and steam to the sawmill; $90 \%$ of the steam used at the sawmill comes from waste heat at the pulp mill, the remainder being divided equally between biofuel and oil.

The companies consider the pulp mill - sawmill integration to be very profitable. Among the advantages mentioned were better use of energy, minimal transport since the wood chips are transported to the pulp mill on a belt conveyor, and efficient use of the harbour.

\section{Integration pulp mill - pellet production plant}

The pulp mill delivers bark, electricity and steam to the pellet production. The steam is used to dry the bark in a steam dryer before grinding and pelletization. The pellets are dried with steam at 11 bars, which means that the electricity production is lowered since this steam could have been used for electricity generation in the turbines. The operation and maintenance costs are 
high due to some problems with the pelletization process since the bark composition causes corrosion in the equipment. As a consequence, the pellet production facility has had a lower availability than expected, and profits have also been lower than expected.

\section{District heating cooperation}

The local energy service company plans to build a district heating network in the municipality. The pulp mill plans to sell district heating from excess steam (16 MW). In the future, the pulp mill could deliver more heat by installing flue gas condensation at the bark boiler. The advantage is that that energy is always available - even during minor disruptions in production.

\section{Some additional comments regarding the energy system}

In addition to pellet production, bark is used as fuel. Most of the bark is burnt in the bark boiler, and due to the prohibition on using combustible material as landfill, the bark boiler is sometimes used for destruction and has to be supported with oil burning. The steam from the bark boiler is used for power production. When dry bark is used, there is an excess of steam which is not used. Some bark is also pulverized and used as fuel in one of the lime kilns. The use of bark depends on prices for different fuels, the type of pulp produced and if timber or woodchips from sawmills are used as raw material.

Steam is produced in the bark boiler and in the recovery boiler (60 bars). There is also a refuse incineration boiler that generates steam at 11 bars. Three turbines produce electricity and low pressure steam. The pulp mill produces an excess of electricity and approximately $3 \mathrm{MW}$ is sold externally. The excess of low pressure steam produced is not used. There is no condensing turbine, and the company has no interest in building one since the pay-back time is too long. However, they seem to be positive to the idea that another company could build the turbine, or that another industry in need of low-pressure steam could be located in the area. 


\subsubsection{Värö}

In Värö, a chemical pulp mill and a sawmill are co-located and partly integrated. The industries have different owners, but are part of the same group of companies. The pulp mill was built in 1972 and the sawmill in 1974. Annual production capacity is 330,000 tonnes of pulp and $210,000 \mathrm{~m}^{3}$ of sawn wood. Approximately half of the raw material for the pulp production is supplied by sawmills in the area; $20 \%$ of it comes from the integrated sawmill. Since a large part of the raw material is wood chips, the bark from the round wood used at the pulp mill is not sufficient and bark has to be bought from external suppliers. The pulp mill plans to increase production, and, if the capacity exceeds 410,000 tonnes, enough round wood will be bought to cover the internal bark needs. The integration is described in Figure 6.

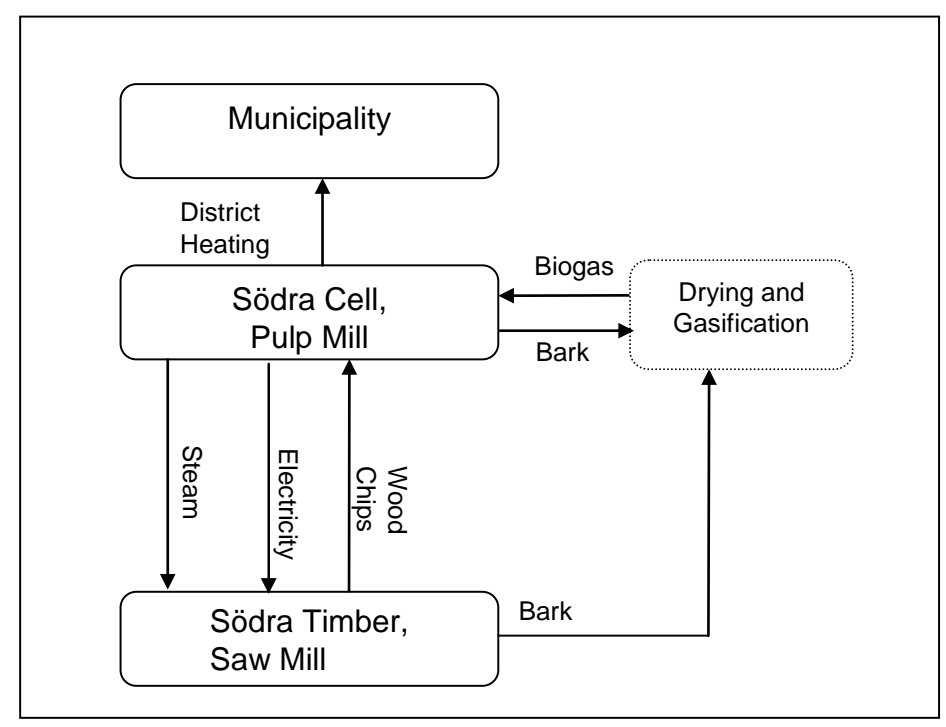

Figure 6. The integration of pulp mill and sawmill in Värö.

\section{Pulp mill - sawmill integration}

The pulp mill delivers steam and electricity to the sawmill. When there are longer disruptions in the production at the pulp mill, the sawmill has to use an oil boiler. The sawdust from the sawmill is sold externally, and the bark from the sawmill is used as fuel internally and in the biogas production at the pulp 
mill. The wood chips and the bark from the sawmill are used in the pulp mill. In addition, the sewage from the sawmill is treated in the sedimentation basin at the pulp mill. As in Mönsterås, the integration saves transportation and leads to more efficient energy use.

\section{District heating cooperation}

When the pulp mill built a new waste water treatment plant, the energy system was changed, which led to a greater excess of heat suitable for district heating. The pulp mill can theoretically supply the municipality with approximately half of the heat demand. The pulp mill supplies both base load and peak load in the district heating network and the energy service company provides backup heating. The project to build a district heating network was partially financed with LIP subsidies (Local Investment Program) and most of the investments were made by the energy service company. The project has been a success, according to representatives from the pulp mill, and has been running without disruption during the first year of operation. This is partly due to the fact that the system was designed to suit the conditions at the pulp mill.

\section{Some additional comments regarding the energy system}

At the pulp mill, the bark is used in a bark boiler and in a biomass gasifier that produces gasified bark for the lime kiln. The process steam is generated in the recovery boiler and bark boiler and in an oil boiler. As in all chemical pulp mills, the recovery boiler is used as base load since it is also a chemical reactor. Approximately half of the incoming round wood is recovered as energy in the recovery boiler.

The pulp mill produces $90 \%$ of the electricity used at the plant. More bark could be burned in the bark boiler to increase the steam production and generate "green" electricity. However, as in Mönsterås, there are no condensing turbines and there is no need for more low-pressure steam. The demand for low-pressure steam thus controls the load in the bark boiler since installing condensing turbines is not considered profitable enough. With new turbines and generators, the electricity demand could be covered. However, new 
environmental regulations or changes in the processes could lead to an increased electricity demand as well.

\subsubsection{Forssjö}

In Forssjö bruk, a sawmill with integrated pellet production is studied. The facility produces $101,000 \mathrm{~m}^{3}$ of sawn wood and 45,000 tonnes of pellets annually. The sawmill that exists today was built in 1985, after an old sawmill at the location had burned down, and the pellet production plant in 1995. The same company owns both the sawmill and the pellet production plant and parts of buildings and some personnel are shared.

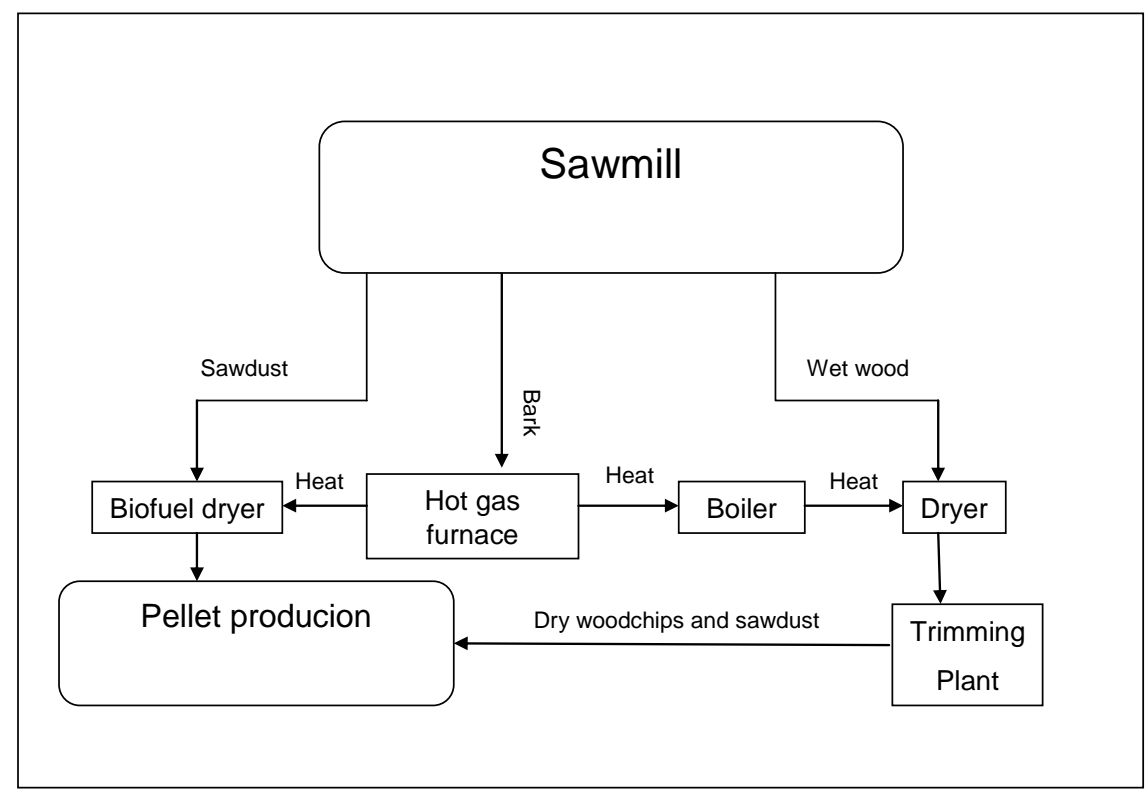

Figure 7. Integrated pellet production and sawmill.

\section{Sawmill - pellet production integration}

The integration is described in Figure 7. Sawdust and dry wood chips from the sawmill are used to produce pellets. The bark is burned in a hot gas furnace and provides both the sawmill and the pellet production plant with energy for drying. The biomass is dried in a rotary drum dryer using flue gases 
from the hot gas furnace. An oil fired boiler provides the steam that is needed in the pelletization process.

The sawmill used to sell sawdust but today only about $20-25 \%$ of the raw material for pellet production is provided by the sawmill; the rest is delivered from other sawmills in the area. The price of sawdust has increased significantly in recent years, and today raw material represents half of the production cost of the pellets.

Once the sawdust is dry, some dry biomass, such as wood chips, is added. The wet wood chips are not used for pellet production; they are sold to pulp mills as raw material. Today, it would not be profitable to make pellets from the wet wood chips due to the expensive equipment needed to grind them. However, in the future, if biofuel prices continue to rise, representatives from the sawmill believe that it could be worth investigating. This would mean competition for the wet wood chips between use as raw material for pulp production and use as biofuel.

The operation and maintenance costs have been higher than expected, and there have been some capacity problems in the dryer. However, the need for maintenance has decreased with greater knowledge of pelletization. The focus in the development has been on quality, productivity and economy. Representatives from the sawmill state that suppliers, customers and producers have all learnt more about pellets, which has increased the quality of the product. They argue that the initial problems were to a large extent related to the new technology and lack of experience.

\subsection{Kisa - development of a local industrial ecosystem}

This section is based on a case study presented in papers II- $\mathrm{III}^{2}$. Kisa is a municipality with several forest industries where there is a potential to initiate the development of a local industrial ecosystem.

The municipality has about 10,000 inhabitants. Several small and medium sized forest industries are located in the area (Table 3): a medium-sized and a small sawmill, a paper mill and two paper processing industries. Apart from 
these, there are other processing industries interested in waste heat etc in the municipality. There are also a local waste management company and an energy service company (ESCO). In addition, an ecocycle company with recycling of waste material as its business concept has made deals with some of the local companies and is therefore included in the study.

Table 3. Forest industry in the studied municipality.

\begin{tabular}{|c|c|c|}
\hline Company & Production/year & Number of employees \\
\hline Sawmill & $\begin{array}{l}\text { - } 170,000 \mathrm{~m}^{3} \text { sawn wood } \\
\text { - } 45,000 \mathrm{~m}^{3} \text { refined } \\
\text { products }\end{array}$ & 120 \\
\hline Paper mill & - 36,000 tonnes & 140 \\
\hline $\begin{array}{l}\text { Paper processing } \\
\text { industry I }\end{array}$ & - approx. 5,000 tonnes & 135 \\
\hline $\begin{array}{l}\text { Paper processing } \\
\text { industry II }\end{array}$ & - approx. 1,500 tonnes & 15 \\
\hline Small sawmill & - $15,000 \mathrm{~m}^{3}$ sawn wood & 8 \\
\hline
\end{tabular}

Some material and energy exchanges already exist in the system today (Figure 8 and Figure 9). The boiler at the paper mill is outsourced to the energy service company, which provides the paper mill with required process steam. The fuel is biofuel, oil and about 20\% waste paper from the paper mill and processing industries. The ESCO also owns a small district heating network in the centre of the town. There are plans to extend this to include the process industries, office buildings in the paper mill and some additional housing areas in the municipality. This way, the existing use of oil at these sites can be reduced or avoided. A new biofuel boiler is planned near the boiler at the paper mill to provide some of the heat needed for the district heating network expansion. Part of the increased heat demand will also come from steam condensing in the existing boiler and a district heat economiser. However, since the paper mill also faces a major expansion it is not certain that the ESCO will be able to supply the heat without increasing the use of oil compared to the situation today. 


\section{System improvements and possibilities for energy flows}

Some of the major existing and possible future exchanges in the energy system are presented in Figure 8. Today, oil is used in the process industries, some housing areas in the municipality and to heat the office buildings at the paper mill. By extending the district heating network, the existing use of oil at these sites can be reduced or replaced. At the sawmill, the process steam and heat needed are produced in a biofuel boiler using some of the internal byproducts as fuel. Additional biofuel by-products from the sawmill are currently sold to particle board manufacturers or to district heating networks in other municipalities as fuel. If used locally, these biofuel by-products could cover the total need for biofuel to supply process industries and the existing district heating network, and fill the steam demand at the paper mill. This could also reduce transport costs and environmental impact compared to the present situation.

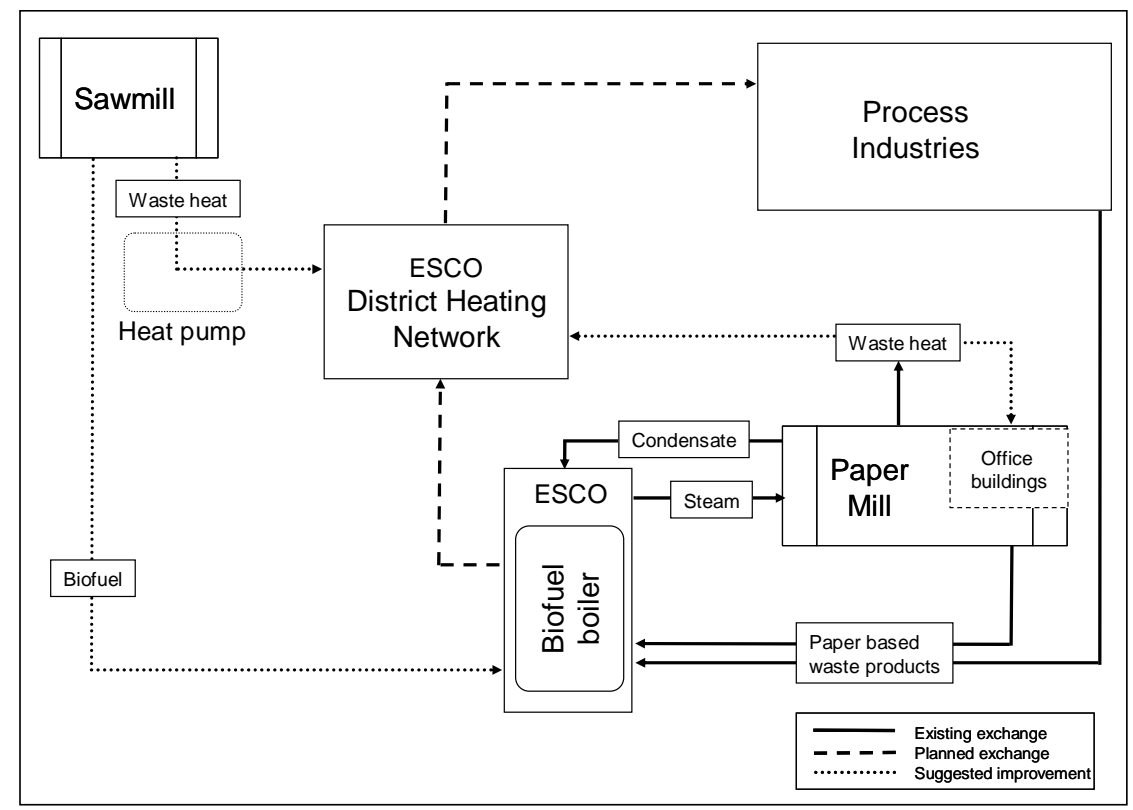

Figure 8. Planned, suggested and existing exchanges in the energy system. 
Waste heat is available today both at the sawmill and at the paper mill. If this waste heat were to be used in the district heating network and in office buildings it would either replace oil directly or save biofuel which could replace oil or other fuels elsewhere in the energy system (assuming that biofuel is a limited resource). Transportation could also be decreased if some additional waste paper from the processing industries were used as fuel in the local biofuel boiler. Today, some of these paper residues are transported 55 $\mathrm{km}$ and burned in a large refuse incineration plant. In addition to the exchanges between industries presented in Figure 8, an industry that requires low-temperature waste heat could be located close to the sawmill.

\section{System improvements and possibilities for material flows}

Some existing, planned and suggested exchanges in the material system are summarized in Figure 9. In addition to these, improved sorting and upgrading of waste at the local waste management site is a possible improvement that would decrease the amount of waste material used for landfill.

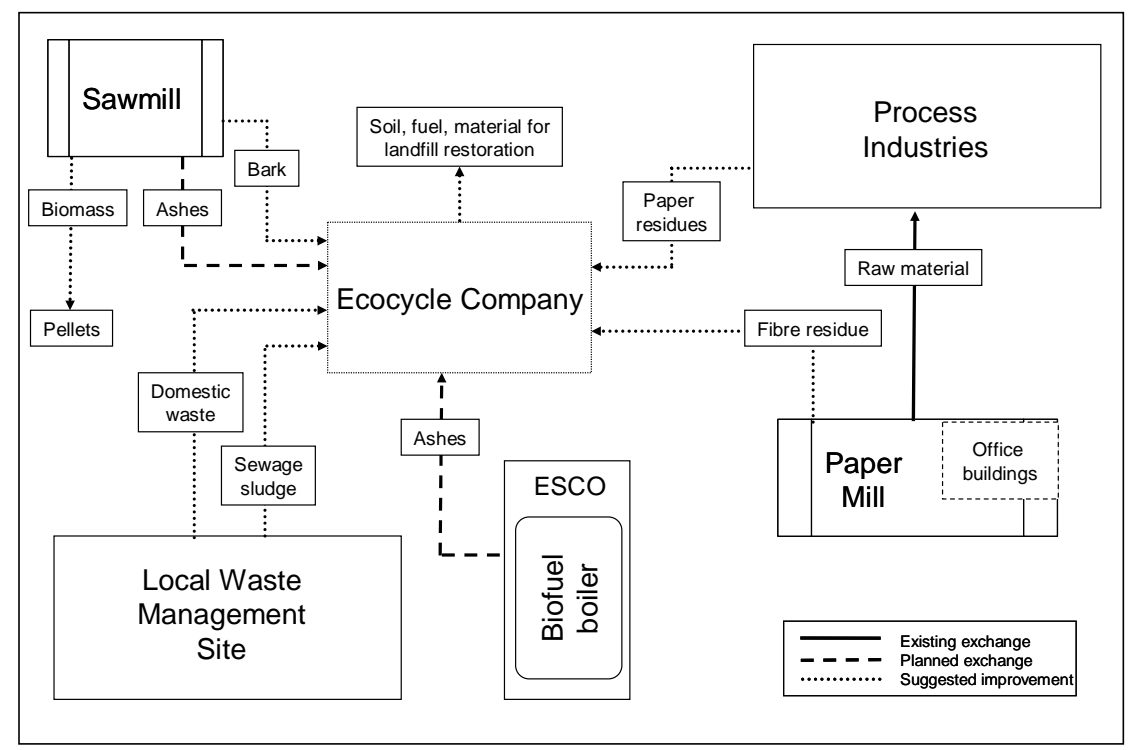

Figure 9. Planned, suggested and existing exchanges in the material system. 
An ecocycle company has made deals with some companies, but currently they have no production unit in the municipality. The establishment of an ecocycle company, or another company with recycling as a business concept could be helpful in the endeavour to use the existing material flows locally. A number of interesting by-products and waste material that could be used more efficiently, by the ecocycle company or at other sites, are presented in Table 4.

Table 4. Possible increased integration and use of the material flows identified in the system.

\begin{tabular}{|c|c|}
\hline Material flow & Possible uses \\
\hline Ashes & 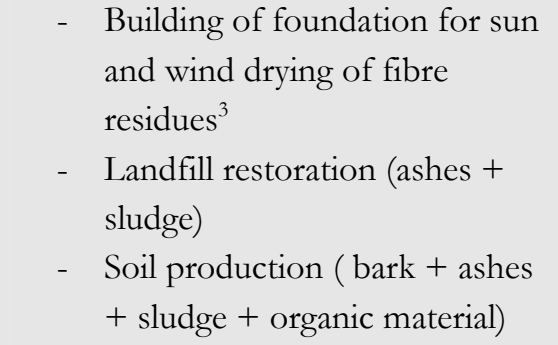 \\
\hline Sewage sludge & 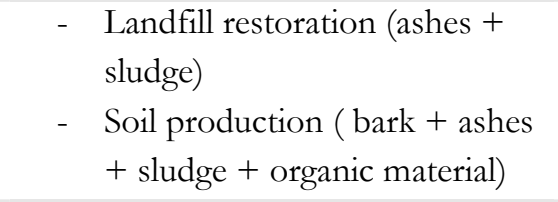 \\
\hline Paper residues from the industry & $\begin{array}{l}\text { - Dehydration of sewage sludge } \\
\text { - } \quad \text { Fuel }\end{array}$ \\
\hline Bark & $\begin{array}{ll}\text { - } & \text { Fuel } \\
\text { - } & \text { Hygienization of sewage sludge } \\
\text { - } & \text { Soil production }\end{array}$ \\
\hline $\begin{array}{l}\text { Fibre from wastewater cleaning at the } \\
\text { paper mill (today shipped to a paper } \\
\text { mill and used for fluting) }\end{array}$ & $\begin{array}{l}\text { - Sun and wind drying } \\
\text { - Use as reinforcement material } \\
\text { for dehydration of sewage } \\
\text { sludge }\end{array}$ \\
\hline Domestic waste & $\begin{array}{l}\text { - Organic material can be used as } \\
\text { soil after composting }\end{array}$ \\
\hline
\end{tabular}

One alternative for efficient use of by-products and energy from the sawmill is to use waste heat and biomass to produce pellets. Assuming a drying process based on flue gas drying (Andersson et al. 2003; Vidlund, 2004) it can be concluded that 24,000 tonnes/year of pellets could be produced from the 
existing sawdust at the sawmill. However the flue gases from the existing boiler can only supply enough heat if the flow is increased or the flue gases are humidified. With existing flue gases, approximately 7,500 tonnes/year could be produced.

\section{Changed material and energy flows}

Over the course of the case study, some new projects started and some changes in the system were implemented.

- Instead of dumping it as previously, the municipality has begun to sell sewage sludge to the ecocycle company for landfill restoration.

- The ashes from the sawmill and the ESCO are now taken care of by the ecocycle company and used to build a foundation for sun and wind drying.

- The ecocycle company has also shown interest in the fibre residue from the paper mill and has made successful tests to use it as reinforcement material for dehydration.

- The district heating system was expanded to include some of the process industries. Originally, the expansion was only planned to include residential areas; however, since some of the process industries expressed a desire to be part of the district heating network, the ESCO decided to extend it further.

\subsection{Discussion}

The inventory presented in section 5.2 identified fifteen BPX networks in the Swedish forest industry. It can be assumed that even more industrial symbiosis initiatives exist. For example, the four field studies made during the inventory all revealed additional exchanges, which were not discovered during the earlier correspondence with the industries since the companies themselves did not consider them "co-operations" or "exchanges", mainly because they existed within the same company, or within what had once been the same company. Perhaps the linking of several companies through the district heating network does not strike representatives of Swedish industry as cooperation being worth any special attention since it is a common arrangement in Sweden. The same question arises for re-use of water, which was one of the 
driving forces in Kalundborg and also contributes to half of the exchanges there (Christensen, 2007). In this inventory, only three cases of water exchanges were found, except for the cases where hot water and steam are energy carriers. This indicates that the arrangements of industrial symbiosis networks, as well as the view of the companies, are dependent on the context in which they exist. More exchanges could probably also be found if smaller sawmills were taken into account. Moreover, exchanges within one industry, such as integrated biofuel upgrading, were not included in the inventory (except the Mönsterås case, which showed up since it has other exchanges as well). By broadening the definition of industrial symbiosis used, it might be possible to identify more examples. Several companies in the inventory have some interesting forms of co-operation, from an environmental point of view, although they do not fit into the framework of the initial definition. For example, seven industries co-operate with adjacent companies on transportation and 18 companies have heat exchanges (only) with adjacent industries.

Chertow (2007) suggests a " $3-2$ heuristic", meaning at least three different entities exchanging at least two different resources, to distinguish industrial symbiosis from linear one-way exchanges. In the inventory presented in paper IV, a company was regarded as being part of a BPX network if it had more than one exchange of material or energy with adjacent industries, or if it was part of a network with several exchanges. Although Chertow's definition is stricter, 14 of the 15 BPX networks could be argued to fit in under her IS definition. The Värö and Mönsterås cases are both identified as BPXnetworks in the inventory, and could also be argued to fit into the IS definition. Neither Kisa nor Forssjö are regarded as BPX networks in the inventory. In Kisa, most of the exchanges were not realized at the time of the inventory; should all the proposed possibilities for material and energy exchange be realized it would count as both BPX network and IS. In Forssjö, the same company owns the pellet production unit, which means it was not identified in the inventory. Since only two entities are involved, it can not be argued to be industrial symbiosis according to Chertow's definition either. However, co-operations revolving around only one or two exchanges could still be a starting point for developing industrial symbiosis. 


\section{EVALUATING THE SUCCESS OF INDUSTRIAL SYMBIOSIS}

In this chapter, the quantitative and qualitative results from the papers concerning environmental and economic performance are presented and discussed in relation to relevant literature.

\subsection{Background}

The benefits of IS can be evaluated either quantitatively or qualitatively. Chertow and Lombardi (2005) suggest that "The environmental benefits of industrial symbiosis are quantified by measuring the changes in consumption of natural resources, and in emissions to air and water, through increased recycling of materials and energy". Although this way of accounting for the benefits may exclude secondary effects, such as efficient use of buildings, personnel, the possibility for common deliveries and use of services which might reduce transportation etc, it is still a reasonable way of simplifying the system and focuses on the effects of industrial symbiosis. There are, however, some difficulties in performing such quantification. In paper VI the complexity of environmental assessment of industrial symbiosis is discussed comparing different tools for environmental analysis and the applicability of these to industrial symbiosis. It is concluded that quantification is problematic for a real-life system since it is hard to discriminate the environmental and financial benefits from IS from other parameters affecting the system. 
Using a model, it is possible to compare the performance of the integrated industrial symbiosis system to the performance of the system directly if all entities are operated stand-alone. However, this may not be entirely fair since different technologies might be advantageous depending on the degree of integration of the system. On the other hand, if the environmental impact of an industrial symbiosis system is evaluated using some kind of measurement on a real life system, it is difficult to see if the environmental benefits are due to the industrial symbiosis or to other factors influencing the companies (cf. Ammenberg 2003 for a similar discussion on standardized environmental management systems). Brings Jacobsen (2006) states that it is difficult to perform a detailed engineering calculation of the effects of the Kalundborg IS since conditions have changed over the years and because access to relevant technical data and decision scenarios is difficult in the historical perspective.

There is also an allocation problem when considering industrial ecosystems and industrial symbiosis, i.e. how the costs and benefits, environmental or financial, from IS should be allocated between the participating entities. Successful profit sharing is crucial for implementation of IS, but also for environmental benefits it is of utmost importance to the participating entities since the environmental performance of specific entities influences taxes, subsidies, environmental consent etc. It is also important in LCA studies of products that are produced in IS systems, where allocation is a classic problem. Ekvall and Weidema (2004) suggest some approaches for the allocation problem in multifunctional approaches. They suggest different approaches, or a combination thereof, for different kinds of multifunctional processes, and for recycling. If the industrial symbiosis system is seen as a multifunctional process with many different products and dependencies, the allocation problem becomes very complex since the relationships between different production units may be complex, including both raw material, byproducts, recycling of waste material, common systems for heat delivery and water use etc all at once.

The issue of system boundaries is present in all systems research. The whole idea of industrial symbiosis can be seen as a systems view of industry; by widening the system boundary a whole area of industries containing several 
entities could be optimized to achieve better economic and environmental performance than if all participating entities were to be optimized separately. However, the question arises of how wide this system boundary should be. If too small, sub-optimizations may occur, and if too wide, the system becomes so complex that it is almost impossible to manage. In paper II it is concluded that it is important to have a flexible system boundary looking at the system from different perspectives and at different levels to find the best uses for existing energy and material streams. When assessing the environmental benefits of industrial symbiosis it is also important to consider the system boundaries to ensure that the systems compared really are comparable. Otherwise there is a risk of inconsistency in the comparison, where the two systems have different boundary conditions or include completely different processes. If processes are added to or removed from the system, alternative uses and production have to be considered. Also, to assure the relevance of the results, it is important to clearly show which system boundaries have been used.

\subsection{Qualitative evaluation of the cases}

From the case studies presented in paper I, concerning integrated biofuel upgrading in the forest industry, some aspects regarding the environmental concerns can be highlighted and discussed. By producing pellets in a biofuel combine use of biofuel and energy is more efficient, which could be argued to lead to reduced emissions of $\mathrm{CO}_{2}$ depending on the assumptions made for alternative use of the biofuel and origin of electricity. Emissions of VOC could also be controlled effectively depending on the drying technique used. However, one of the cases showed that there may be a conflict between local and global environmental issues (depending on the choice of technology), where the companies have stronger incentives to limit local emissions given the way the policy instruments of today are designed. In all the cases, transports were reduced since by-products were used locally as raw materials.

In the Kisa study, some of the improvements suggested can have immediate economic effects on the companies involved, such as the possibility for the paper mill to sell fibre residues, which they have to pay to dispose of today, to the ecocycle company. Selling ashes to the ecocycle company is a solution to a 
problem the municipal authority had at the waste management site. Land filling of ashes is heavily taxed which made it desirable for the municipality to dispose of the ashes in some other way. Some of the measures lead to gains that are more indirect from an economic point of view, and more direct from an environmental point of view. The minimization of transportation through the local use of biofuel has environmental advantages, but the companies involved may see no direct economic effects since they do not pay for the transportation anyway.

In the inventory no specific evaluation was made. However, from the nature of the exchanges found some conclusions about the effects may be drawn. Several of the exchanges mentioned revolve around electricity and steam. Apart from the BPX networks, several other heat exchanges were also found. Since the forest industry, especially the pulp and paper mills, are very energy intensive, there is substantial potential for savings. When waste heat from the forest industry is used in district heating networks, or in other processing industries, this saves fuel which might be used elsewhere in the energy system. How large the savings, for example in $\mathrm{CO}_{2}$ emissions, are varies from case to case and depends on the system boundaries and the assumptions used in the calculations. However, when waste heat is used in the energy system, instead of being released into the air or water, this can be argued to always be efficient from a resource perspective ${ }^{4}$.

The use of by-products from sawmills, such as woodchips and sawdust, may lead to reduced transportation locally compared to if they were to be sold to industry elsewhere. Some exchanges, such as sludge from the pulp mills used as fuel, soil fertilizer, and for covering material at landfills reduce the amount of waste produced since this by-product has no alternative use.

\subsection{Quantitative assessment}

To evaluate industrial symbiosis in the forest industry a case study was performed using the MIND method on a model of an industrial symbiosis system with a chemical pulp mill, a sawmill, a biofuel upgrading plant and a possible connection to a district heating system. 
A schematic picture of the system is shown in Figure 10, including possible material and fuel exchanges in the system. The economic and environmental (limited to $\mathrm{CO}_{2}$ emissions) performance of the system operated in stand-alone mode is compared to the performance when operated as an industrial symbiosis system with the different plants integrated. The system boundary is drawn to include all the entities both in the integrated and stand-alone cases. Prices and costs are input data in the economic evaluation, and in the environmental evaluation effects on the surrounding energy system are considered by accounting for emissions connected to electricity production and alternative use of biofuel.

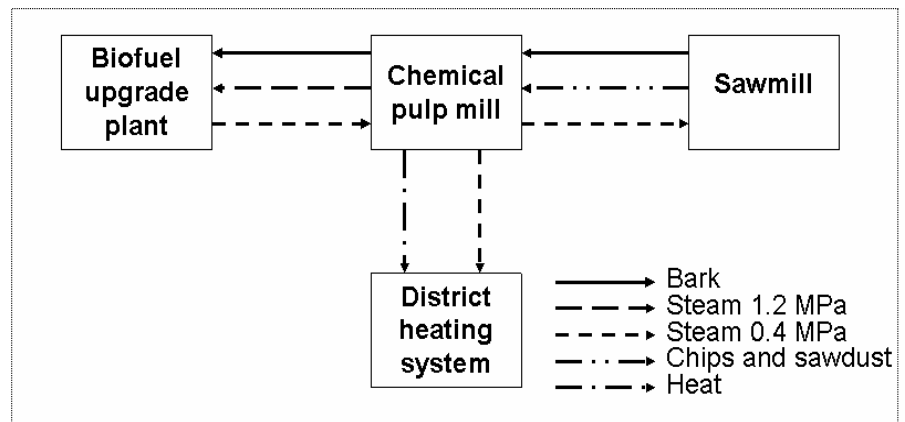

Figure 10. A schematic picture of the system including possible material and fuel exchange. The system boundary used in the study is drawn around all subsystems.

\subsubsection{Model input data}

The models are based on data for standard stand-alone plants. Input data for the different plants is taken from existing plants in Sweden. The biofuel upgrading plant is adjusted somewhat to fit the purpose of this study. Prices of energy and material have been adjusted according to Table 5 . 
Table 5. Price of different energy carriers.

\begin{tabular}{ll}
\hline Energy carriers & Prices (Euro/MWh) \\
\hline Electricity & 34 \\
Bark & 12 \\
Oil & 21 \\
Wood Chips & 15 \\
Sawdust & 14 \\
\hline
\end{tabular}

To illustrate the differences in results depending on the assumptions made, different emissions accounting models are used for the $\mathrm{CO}_{2}$ in the environmental evaluation. The carbon dioxide emissions from different fuels can be found in Table 6 (IPCC, 1997). Based on the $\mathrm{CO}_{2}$ emission factors and on the efficiencies of different production units, the $\mathrm{CO}_{2}$ emissions from heat and power production can be calculated. In Table 7 , the $\mathrm{CO}_{2}$ emissions from electricity depending on the assumed model for alternative power production are presented. Average data are often used for environmental assessment in practice $^{5}$ and might also be appropriate for descriptive studies, although this can be discussed. Some kind of marginal data are often more appropriate when change-oriented studies are made (e.g. Sjödin and Grönkvist, 2004; Finnveden and Moberg, 2005; Ekvall et al. 2005). For Sweden, coal condensing power has been assumed to be the short-term marginal power production, and for longer time perspectives, taking new technologies into account, Natural Gas Combined Cycle is the marginal power production (SEA, 2002).

Table 6. $\mathrm{CO}_{2}$ emissions from different fuels (IPCC 1997).

\begin{tabular}{ll}
\hline Fuel & $\mathrm{CO}_{2}$ emission factor $\left(\mathrm{kg} \mathrm{CO}_{2} / \mathrm{MWh}\right.$ \\
& fuel $)$ \\
\hline Bituminous coal & 341 \\
Residual fuel oil & 279 \\
Dry natural gas & 202 \\
Biofuel & 0 \\
\hline
\end{tabular}


Table 7. $\mathrm{CO}_{2}$ emissions from electricity for different accounting models.

\begin{tabular}{lllll}
\hline Model & $\mathrm{CO}_{2}$ emissions & $(\mathrm{kg}$ & $\mathrm{CO}_{2}$ & $/ \mathrm{MWh}$ \\
& electricity) & & & \\
\hline Marginal Coal & $974^{*}$ & & & \\
Marginal New Technology (NGCC) & $337^{*}$ & & \\
Average Swedish Production & $11^{* *}$ & & \\
\hline
\end{tabular}

* Calculated from Grönkvist et al. (2003)

** SEA (2000)

Also, another model is used where it is assumed that biofuel is a limited resource (Grönkvist et al. 2003). The reason for this is that the commonly used assumption that the net $\mathrm{CO}_{2}$ emissions from biofuel are zero is only true if the biofuel used is re-grown at the same pace as it is being used, and as long as biofuel is an unlimited resource. This assumption also leads to the questionable conclusion that there is no reason, from a $\mathrm{CO}_{2^{-}}$and resource perspective at least, to use the biofuel as efficiently as possible. However, if biofuel is a limited resource it would mean that biofuel saved could replace some other type of fuel in the system, and the other way around - if additional biofuel is needed, it has to be taken from some other unit, leading to that unit having to use other fuels instead. Grönkvist et al. (2003) argue that a comparison with coal would be natural since biofuel may replace coal in many applications without any extensive technical modifications. Therefore, in the limited biofuel model, $\mathrm{CO}_{2}$ emissions from biofuel have been assigned the same values as for coal.

The production rate is fixed during modelling and as the study is based on comparisons between different cases, revenues from selling wood pellets, pulp and timber is not included. One production year is modelled, which represents a year when an overhaul period of 14 days is excluded from the calendar year. This is a result from the operation of the chemical pulp mill, and is also assumed for the biofuel upgrade plant and the sawmill in the case study. The year is divided into 28 different time steps to reproduce the changes within the system, e.g. the district heating network demand (see paper V). 


\section{Chemical pulp mill}

The values for the pulp mill are taken from material at an existing mill and from information received from the staff and then processed to fit into the models. The production rate is assumed to be constant 59 tons/h giving an annual production of approximately 500,000 tonnes.

At the site there is one steam boiler combusting oil and bark, with an efficiency of between $74 \%$ and $83 \%$, dependent on the fuel used. There are two recovery boilers, which are modelled as one with an efficiency of around $69 \%$. The recovery boilers combust black liquor and gases, produced within the mill. Also, some oil is burnt for stability and for starting up the boilers. The recovery boilers and the steam boiler use electricity for fans and pumps. Black liquor is produced continuously within the production process at the mill and needs to be combusted almost immediately. As a result, at times with low demand on steam at the mill, there is a possibility that steam is dumped.

The steam produced may be expanded in a turbine, which has a maximum electrical power output of $46 \mathrm{MW}$. The part of electricity produced in the turbine that is based on renewable sources qualifies for green certificates (Swedish Government Energy Bill, 2003). Green certificates have been introduced in Sweden to promote electricity production from renewable sources. Electricity produced in such a way receives an additional income. In the model this income amounts to 230 SEK per MWh electricity produced; in reality, however, the price is market-based and varies.

\section{Sawmill}

The sawmill in this study is based on data from an existing sawmill with an annual production of $100,000 \mathrm{~m}^{3}$ sawn wood. When producing timber different by-products are produced: bark, chips and sawdust. In the model this is represented as follows: each log entering the mill creates $9 \%$ bark, $28 \%$ chips and $12 \%$ sawdust, while the rest, $51 \%$, is timber. Heating values for the by-products are calculated from information provided by staff at the sites. In the stand-alone sawmill, heat for drying sawn timber is produced in a biofuel boiler at the site, using by-product biofuel such as sawdust, bark and wood chips. 


\section{Biofuel upgrade plant}

In the biofuel upgrading plant, bark pellets are produced, although in this model the drying of the biofuel is in focus and the pelletization process is only considered in the model generating an electricity demand. In the stand-alone case, heat for the drying of the wet bark originates from a biofuel boiler at the plant, and as a result some of the raw material for the process is used for heat production. To produce one ton of pellets 3.55 tons of bark is used (calculated based on information from staff at a plant). The modelled production of wood pellets at the biofuel upgrade plant is 40,000 tons/year.

\section{District heating system}

Just like the plants, input data for the district heating system is taken from a real system. It is a small system, equivalent to $22 \mathrm{GWh}$ per year. In the real life system, heat is delivered from a chemical pulp mill, like in the industrial symbiosis in the model. For reasons of comparison it is assumed that the heat needed for the district heating system is covered by an oil boiler, with the same characteristics as the oil boiler at the chemical pulp mill, in the standalone district heating system in paper V. In paper VI it is assumed that the base load of the heat needed is covered by a bio fuel boiler, and the peak load is covered by an oil boiler.

\section{Industrial symbiosis}

When integrating the biofuel upgrading plant and the sawmill with the chemical pulp mill some adjustments and assumptions need to be considered. Through spreadsheet calculations, based on net heat demand for drying a specific amount of pellets and real figures from existing plants, it is calculated that $74 \%$ of the steam needed by the biofuel upgrade plant is recovered as low pressure steam and is delivered to the grid at the chemical pulp mill. The possible amount of district heat extracted from the biofuel upgrade plant, when integrating it with the pulp mill, is calculated, using a spreadsheet, to $10 \%$ of the steam need for the biofuel upgrade plant.

The sawmill has the possibility to deliver bark and sawdust to the steam boiler at the chemical pulp mill. Chips, on the other hand, can be delivered to the 
cooking process at the chemical pulp mill in the industrial symbiosis cases. Selling bark, chips, and sawdust is also possible in the integrated cases.

\subsection{Economic evaluation}

For the economic evaluation, some different cases with different degrees of integration were compared (Table 8).

Table 8. Different cases evaluated in the case study. $\mathrm{X}$ indicates that the specific subsystem is integrated with at least one other subsystem.

\begin{tabular}{ccccc}
\hline Case & Chemical pulp mill & Sawmill & $\begin{array}{l}\text { Biofuel } \\
\text { upgrading } \\
\text { plant }\end{array}$ & $\begin{array}{l}\text { District } \\
\text { heating } \\
\text { system }\end{array}$ \\
\hline 0 & Stand-alone & Stand-alone & Stand-alone & Stand-alone \\
1 & $\mathrm{X}$ & Stand-alone & Stand-alone & $\mathrm{X}$ \\
2 & $\mathrm{X}$ & $\mathrm{X}$ & Stand-alone & Stand-alone \\
3 & $\mathrm{X}$ & $\mathrm{X}$ & Stand-alone & $\mathrm{X}$ \\
4 & $\mathrm{X}$ & Stand-alone & $\mathrm{X}$ & Stand-alone \\
5 & $\mathrm{X}$ & Stand-alone & $\mathrm{X}$ & $\mathrm{X}$ \\
6 & $\mathrm{X}$ & $\mathrm{X}$ & $\mathrm{X}$ & Stand-alone \\
7 & $\mathrm{X}$ & $\mathrm{X}$ & $\mathrm{X}$ & $\mathrm{X}$ \\
\hline
\end{tabular}

Since the system boundary is drawn to include all subsystems (Figure 10), the total system cost includes all subsystems (chemical pulp mill, the sawmill, the biofuel upgrading plant and the district heating system). For example, the total system cost for Case 5 represents the cost for the sawmill (stand-alone) added to the cost for the integrated chemical pulp mill, biofuel upgrade plant and district heating system. The total system cost for each case is then compared to the total system cost for the stand-alone case, i.e. Case 0.

Table 9 shows the difference between the cases and the reference case (Case 0 , where all entities operate stand-alone) for the total system cost, electricity production and steam dumping in the pulp mill. It can be seen that the system cost decreases in all the industrial symbiosis cases. Integrating the district heating network (cases 1, 3, 5 and 7) in particular lowers the cost compared to the similar systems without a district heating network. The decrease in system cost depends on changes in electricity production, decreased steam dumping 
and changes in fuel use and fuel sales as well as differences in the use of waste heat. The system with lowest cost is the fully integrated industrial symbiosis system (Case 7). Case 7 also has the lowest amount of waste heat and steam that is being discharge.

Table 9. Results of the modelled cases compared to the reference case (Case 0 ).

\begin{tabular}{llllll}
\hline Case & $\begin{array}{l}\text { Decrease } \\
\text { in system } \\
\text { cost }[\%]\end{array}$ & $\begin{array}{l}\text { Increase in } \\
\text { electricity } \\
\text { production } \\
{[\%]}\end{array}$ & $\begin{array}{l}\text { Decrease } \\
\text { in steam } \\
\text { discharge } \\
{[\%]}\end{array}$ & $\begin{array}{l}\text { Decrease in } \\
\text { discharge of } \\
\text { waste heat }\end{array}$ & $\begin{array}{l}\text { Increase in } \\
\text { bark sales } \\
{[\%]}\end{array}$ \\
\hline 1 & 6.5 & 0.9 & 10.6 & 26.3 & 4.9 \\
2 & 5.5 & 1.5 & 56.8 & 0.1 & -6.1 \\
3 & 13.5 & 1.7 & 56.8 & 71.7 & 23.0 \\
4 & 3.8 & -1.0 & 21.2 & 0.1 & 45.2 \\
5 & 10.8 & -0.3 & 23.8 & 43.1 & 57.8 \\
6 & 9.3 & 0.5 & 78.0 & 0.1 & 39.2 \\
7 & 17.6 & 0.5 & 78.0 & 80.4 & 72.8 \\
\hline
\end{tabular}

\section{Sensitivity analysis}

The main focus in the simple sensitivity analysis performed in this study is on the energy prices. Other parameters that are possible to analyze are changes in production volume for the different plants and internal changes, such as more energy efficient solutions for process units. Investments in boilers with better characteristics and/or using another type of fuel, changes in the turbine construction to better correspond to the heat demands, and alternative sizes of the storages could also be analyzed. However, the input data used to model the plants in the analysis are taken from existing plants and the main objective of this study is to evaluate whether it is advantageous to connect different kinds of existing plants to each other. Therefore, only boundary conditions, such as energy prices, are tested in the sensitivity analysis. Table 10 shows the different parameters and the corresponding changes. The changes in prices are relatively high, but not unrealistic considering the variations in market prices over the last decades. 
Table 10. Parameters changed in the sensitivity analysis.

\begin{tabular}{lll}
\hline Parameter & Value & Value \\
\hline Price of electricity & $-50 \%$ & $+50 \%$ \\
Price of oil & $-50 \%$ & $+50 \%$ \\
Price of bark & $-50 \%$ & $+50 \%$ \\
Green certificate $^{1}$ & 0 Euro/MWh & \\
\hline
\end{tabular}

${ }^{1}$ Setting the parameter Green certificate to 0 Euro/MWh is done to represent a case where no green certificates are included in the system.

Table 11 shows the changes in the system cost, compared with Case 0 , when some parameters are changed.

Table 11. Changes in the system cost when changing some parameters and compared to the original cases, i.e. Case 7 (industrial symbiosis within all entities) and Case 0 (stand-alone) without changes in any parameter.

\begin{tabular}{lcc}
\hline Parameter & Case $7[\%]$ & Case $0[\%]$ \\
\hline Price of electricity $(+50 \%)$ & -27.3 & -32.7 \\
Price of electricity $(-50 \%)$ & 27.3 & 32.7 \\
Price of oil $(+50 \%)$ & 0.0 & -4.2 \\
Price of oil $(-50 \%)$ & 4.9 & 8.4 \\
Price of bark $(+50 \%)$ & 12.5 & 12.0 \\
Price of bark $(-50 \%)$ & -7.4 & -6.3 \\
Without green certificates & -100.3 & -117.3 \\
\hline
\end{tabular}

The main conclusions that can be drawn from the sensitivity analysis are that the stand-alone cases are more effected by changes in fuel prices and removal of the green certificates, with one exception; the price of bark. Higher oil and electricity prices make the benefits of industrial symbiosis even higher, whereas the bark price affects the integrated system slightly more than the stand-alone system. It can also be seen that the green certificates have a significant influence on the results; the stand-alone system being more affected by the removal of the green certificates than the integrated industrial symbiosis system. 


\subsection{Environmental evaluation}

Although the environmental assessment of IS is problematic, as discussed in paper VI, an attempt at quantification is made here. The evaluation is simplified by using only the indicator $\mathrm{CO}_{2}$ emissions. By using a model, the effects from increased integration can be decoupled from other parameters affecting the performance of the system.

To illustrate the influence of different assumptions on the results when analyzing the environmental effects of a specific system, the $\mathrm{CO}_{2}$ emissions from the fully integrated system (comparable to case 7 in the economic evaluation) are calculated using different assumptions regarding origin of electricity and emissions from biofuel (Table 12). In all cases, the results show that less $\mathrm{CO}_{2}$ is released from the integrated system compared to the standalone system. In all the cases, less steam is dumped from the pulp mill in the industrial symbiosis system compared to the stand-alone system, since the excess steam can be used in the DHN and for drying wood and biomass at the sawmill and at the biofuel upgrading plant.

Table 12. Decrease in $\mathrm{CO}_{2}$ emissions from the integrated system compared to the stand-alone system.

\begin{tabular}{lll}
\hline Model & $\begin{array}{l}\text { Biofuel unlimited } \\
\text { ton } \mathrm{CO}_{2} / \text { year }\end{array}$ & $\begin{array}{l}\text { Biofuel limited } \\
\text { ton } \mathrm{CO}_{2} / \text { year }\end{array}$ \\
\hline Marginal Coal & 4600 & 26000 \\
Marginal NGCC & 1700 & 25000 \\
Average Grid & 160 & 37000 \\
\hline
\end{tabular}

In the Biofuel Unlimited cases, the savings in $\mathrm{CO}_{2}$ for the industrial symbiosis are largest when marginal coal is assumed to be the alternative electricity production, and lowest if data for average Swedish electricity production is assumed. The reason for this is that the pulp mill produces electricity, which in the Biofuel Unlimited cases is assumed to have net zero emissions of $\mathrm{CO}_{2}$ since it is biofuel based. These assumptions imply that more electricity is produced in the integrated cases, and the amount of electricity that has to be purchased from the grid is lower. Naturally, this influences the results more in the Marginal Coal case than in the Average Grid case. 
Generally, savings are much larger in the Biofuel Limited cases. The reason is that the stand-alone DHN generates much higher emissions if biofuel is considered a limited resource (since the base load of the DHN is biofuel), and thus the incentives of using waste heat from the pulp mill in the DHN are higher than if biofuel is considered an unlimited resource. In the Biofuel Limited cases, the savings in $\mathrm{CO}_{2}$ are larger in the Average Grid case than in the Marginal NGCC case and the Marginal Coal case. This depends on the electricity produced in the pulp mill, which in these cases generates higher emissions than electricity from average Swedish production and NGCC (since the biofuel used is assigned the same value for $\mathrm{CO}_{2}$ emissions as coal). This also leads to an increase in the amount of electricity purchased by the pulp mill, which means that they no longer have any incentives to produce electricity from biofuel internally.

\subsection{Discussion and conclusions from the evaluation}

The results from the economic evaluation show that the integrated industrial symbiosis systems have financial benefits compared to the stand-alone plants when considering the different operational strategies. The results from the environmental evaluation also support the theory that there can be environmental benefits to industrial symbiosis, based on operation mode. It can furthermore be argued that industrial symbiosis initiatives could be even more advantageous than what can be concluded from the results of these examples. For example, benefits such as sharing of buildings, personnel and infrastructure, or reduced transportation were not considered in the model. Also, the model in this study was based on data for standard stand-alone plants since most examples of eco-industrial parks in the industrial symbiosis literature are brownfield redevelopments, i.e. retrofittings of existing industrial parks, and the technologies in these industries can therefore be assumed to be based on stand-alone operation. In greenfield development, i.e. establishing new examples of industrial symbiosis, or when new investments are made, the technologies used can be optimized for integration and it can thus be expected that an integrated system could be even more advantageous. However, there are also possible disadvantages to IS which have not been considered in this study, such as additional investments, transportation losses, risk, a conflict of interests between different entities as regards operational 
strategies and, in a wider perspective, loss of flexibility and risk of interlocking.

One result from the sensitivity analysis in the economic evaluation is that the changes in the system cost are greater in the stand-alone configuration than in the industrial symbiosis configuration for the major part of the parameters (five out of seven) altered. This indicates that the industrial symbiosis system is more stable than the stand-alone system and less affected by changes in boundary conditions. The sensitivity analysis also shows that both system configurations benefit from the green certificates received from biofuel based electricity production in Sweden. However, the industrial symbiosis system is less sensitive to the removal of green certificates, which could be interpreted as green certificates benefiting the stand-alone configurations more; however the difference is not significant.

The main conclusion from the environmental evaluation is that there are large variations in the amount of $\mathrm{CO}_{2}$ released depending on the boundary conditions chosen. Given the simplified system, the fact that environmental impact was simplified to include only $\mathrm{CO}_{2}$ emissions, and that the model reflected only variations in operational strategy, the fact that the results vary so widely indicates that in reality, it would be almost impossible to satisfactorily assess all environmental impacts from industrial symbiosis, especially given the difficulty in reality to discriminate the effects of IS from other parameters affecting the performance of the system. Nevertheless, environmental assessment is an important tool for decision makers and, assuming that great care is taken in choosing and accounting for assumptions, the MIND method is suitable for evaluation of industrial symbiosis. 


\section{GETTING THERE - ON THE IMPLEMENTATION OF INDUSTRIAL SYMBIOSIS}

This chapter discusses how the ideas of industrial symbiosis could be implemented and how industrial ecosystems could be developed. The non-technical parts of the results from papers IIII are presented.

\subsection{Human dimensions}

In order to implement industrial symbiosis the barriers to integration have to be overcome. The human dimensions of industrial symbiosis are important and understanding of the factors that influence decision makers are crucial. Also, the results from the case study in Kisa showed that a technical analysis of the system was not enough to find the optimal ways to integrate. The simultaneous analysis of energy and material systems sometimes gives several options for a flow, and this can lead to a choice as to which alternative is the best. Some flows can for example be considered to be both energy sources and raw material. It may thus be difficult to decide which alternative is the most efficient or best since this is often a question of priorities. It was also clear from discussions of the suggestions with different actors that such issues as historical attempts to change the system and future plans for expansion or other changes in the industries' production are also important in order to develop a system that is efficient in a longer perspective. A good knowledge of the system is important, as well as analyzing the system at different system levels and in agreement with the local actors. 


\section{Attitudes to co-operation}

Most actors in the case studies, both from industry and the municipal authorities, seem to think co-operation is positive. This is vital for the possibility to increase integration between the companies. The results from the study presented in papers II-III also indicate that the commitment of different people is important in order to realize the proposed measures and start co-operations. This confirms what previous research has shown about the importance of enthusiasts to form inter-organizational co-operations (see e.g. Grönkvist et al. 2001 for a study on energy related co-operations). It was also clear from the study presented in paper I that one important factor for the realization of biofuel combines was organizations' willingness to act.

\section{The importance of time frames for investments}

One factor that was found to be important in this study was the investment time frame. Energy investments are often substantial and long-term and projects often have a time restriction, especially if subsidies such as LIP (Local Investment Program) are involved. Because of this, timing is vital for an investment with more than one actor involved to be realized. It seemed important that the companies are in the same phase regarding expansion and investments and the window of opportunity was often small. When, for example, the district heating network in the Kisa study (presented in paper IIIII) should be expanded there were two possible sources of waste heat that could be used; the paper mill or the sawmill. The paper mill was on the verge of a major expansion themselves and did not want to commit to a long-term contract before they knew if they could use their waste heat internally, and at the sawmill the existing boiler was considered too old. However, if the sawmill needs to invest in a new boiler in the future, or if the paper mill realizes that they still have waste heat available, the energy service company might already have decided on another solution. Once a new boiler and piping have been built, the technological lock-in will make any changes in the system difficult.

For the biofuel combines (Paper I) the time scale was also an important factor. Policies and market demand at the time of the decision making were important driving forces. There was also an investment demand at the 
companies at the time. The most obvious driving force in the cases studied here was a surplus of by-products, that could be upgraded to a more valuable product, and excess heat at the time. However, at the time of the study, the market demand and the price of the by-products had changed, meaning that the companies would probably not have chosen to invest in a biofuel combine at the time of the study.

\section{The role of profits and profit sharing}

It was seen from the case studies that there is more to "profit" than economic calculations. On the one hand, obstacles identified in the study on biofuel combines, presented in paper I, include low profitability and high risk due to the instabilities in the biofuel market and the high investment costs, which make it hard to meet the short payback periods required in the forest industry. On the other hand, one of the informants in that study meant that it was more a question of performing calculations that made the projects one wanted to initiate seem profitable (at least for smaller projects). Another way to get round the problem of the short payback times was to show that the biofuel combine is a way to develop the company within the present strategy, since longer pay back times were allowed for strategic investments.

In the local industrial ecosystem study (Papers II-III), the issue of profit sharing was an important factor. A representative of the local energy service company stressed the importance of everybody gaining something from a cooperation. First, the total profit must be calculated and then shared between the actors involved. One of the reasons why a possible waste heat exchange identified in this study was never realized was that the two actors involved could not agree on the value of the waste heat.

\section{Local roots and power relations in the companies}

The Kisa study (papers II-III) indicates that local roots and a possibility to build on personal relations and trust are important factors for industrial symbiosis. One actor commented that a problem with new co-operation projects is that it takes a long time to build up partner relations. Weak local roots can also make a company unattractive in exchange networks since it is 
not certain that it will remain in the area. If one link in an exchange network fails this could damage the performance of the whole system (Lowe, 1997).

The Kisa study showed that co-operation is complicated when a company is part of a larger, centrally governed, corporation, or changed ownership. In the energy service company, the representative responsible for participation in this project changed several times due to restructuring. As a result, the person responsible for energy matters had insufficient local knowledge and was not informed of what waste heat sources or companies existed in the area when the decision was made to expand the district heating network. Another problem encountered in this study is that companies tied to larger corporations can be bound by agreements in the group, for example to deliver by-products or buy raw material, which may impede local use. This supports what Möllersten and Sandberg (2004) found when studying outsourcing agreements between energy service companies and pulp and paper mills. They concluded that small-sized mills, which are not part of larger groups, showed more interest in partnerships.

\section{Environmental regulations}

Several of the actors cited difficulties in acquiring development consent from regional authorities as an obstacle to some of the efficiency improvements suggested in this study. Examples include the use of ashes and sludge for landfill restoration and the possibility to use biomass-based waste products as fuel locally. Previous studies have shown that the process of acquiring a development consent in Sweden is strictly locally oriented and does not take into account secondary effects and improvements that can only be identified if larger systems are taken into account. This might exclude issues such as use of natural resources (Bruhn-Tysk and Eklund, 2000; 2002). The existing environmental regulations do not encourage increased integration between different actors since they are focused on a specific company or process. That the legislation is imperfect has also been mentioned by the authors of earlier studies in the field of industrial ecology (e.g. Lowe, 1997; Esty and Porter, 1998; Burström and Korhonen, 2001). 


\subsection{Strategies for development of industrial symbiosis initiatives}

The fact that most existing examples are self-organized does not necessarily imply that there is nothing to be done in the area of development. For example, Chertow (1999b) argues that evolutionary approaches are the key to development of industrial symbiosis, and suggest that great promise lies in projects where some type of synergy already exists ("green twinning" or "byproduct synergy"). In this work, mainly two approaches to development of IS initiatives are discussed, based on the evolutionary approach and taking existing exchanges as their starting point: the 'side-in' approach and the anchor tenant approach.

\subsubsection{The 'side-in' approach}

One of the possible advantages of industrial symbiosis can be to strengthen the local economy and obtain an environmental profile, as the success of Kalundborg has shown. This can help attract new business and be a marketing advantage for the existing companies, which is difficult to value in money (c.f. Deutz and Gibbs, 2004; von Malmborg, 2004). These assumptions were the starting point of the study presented in papers II-III, where a local industrial ecosystem was developed. Several different actors are involved and the integration concerns the material and energy exchanges presented in section 5.4. The local industrial ecosystem project was only in a start up phase at the time of the study, and most of the possibilities for increased integration were not yet implemented. Part of the study was therefore also to take an active part in the project and in this way evaluate the approach used for development. Drawing upon the theories presented above about organization, and on the conclusions about the importance of a willingness to act on the part of the companies, we developed an approach which uses a 'side-in' strategy (i.e. neither bottom-up nor top-down) taking as the starting point the existing companies and exchanges in a local system. These were analysed, and suggestions for improvements and further development into an industrial ecosystem were made involving the companies and local actors as much as possible. The approach can be summarized in the following steps: 
1) First, important actors, mainly in the forest industry sector, were contacted. Criteria for selection of the actors included that they handle significant amounts of organic matter as raw materials or waste. Most actors were forest industries or had a close connection to the forest industry. New actors were identified through interviews with the main actors. This process was continued until no new actors deemed to be of interest could be found in the municipality.

2) The internal processes of the main actors were analyzed for possible improvements. This was done in order to avoid sub-optimizations and unhealthy dependencies. It is a problem mentioned in industrial ecology literature that unhealthy dependencies can develop where one industry is forced to produce waste which is needed by another industry in the network, leading to a technological lock-in where it is difficult to implement new, more efficient technology. (O’Rourke et al. 1996; Lowe, 1997).

3) The relevant energy and material flows in the municipality were mapped. At this stage it is important to consider size, quality, character, duration and variation over time as well as present and possible future uses for the flows.

4) Existing co-operations, material and energy exchanges and competitive situations were studied.

5) Possibilities for improvements in terms of increased integration between different actors were identified. The importance of identifying some different possibilities for integration development was seen. These development strategies were presented and discussed with the existing actors involved and necessary modifications were identified.

6) A forum where the actors can meet was initiated. It is important that the actors are given the possibility to make new contacts and build up trust that facilitates co-operation. 
A case study of a potential local industrial ecosystem was used to further develop and evaluate the approach by studying the progress of the integration project: what changes were made, what means of improvement had been found, and how useful these were. It was seen that one of the most important steps was the forming of a forum where the actors could meet. Indeed, only by getting local actors together discussions about possible integration projects were initiated. In addition to the steps used here, some additional ideas could also be implemented:

- Knowledge about legislation, taxes and existing subsidies is important, as well as increased awareness of the possible advantages of increased integration. Therefore, an important step would be to identify the need for specialized knowledge improvement.

- A strategy should be developed for profiling, developing and recruiting new actors. A long-term plan with alternative solutions is important to cover for industries that change their production or leave the network. By attracting actors who can use waste products or low temperature waste heat, environmental advantages can be achieved at the same time as the development in the region is strengthened.

\subsubsection{The anchor tenant approach}

Several authors suggest that an industrial ecosystem should be organized around a key actor, or 'anchor tenant' (physical and/or institutional), such as a large industry. In addition to large industries, actors such as municipal authorities and business associations have been suggested as potential anchor tenants. (e.g. van Leeuwen et al. 2003; Boons and Baas, 1997; Chertow, 1999a; 1999b; Burström and Korhonen, 2001; Korhonen, 2001b; von Malmborg, 2004).

In the fifteen networks identified in the inventory (Paper IV, section 5.2), there are five pulp mills, two paper mills, nine integrated pulp and paper mills, thirteen sawmills, one particleboard manufacturer, and four bio-fuel producers. It is difficult to judge whether the sawmills or the pulp and paper industry are the central actors in the networks. The by-products from the 
sawmills are used as fuel and raw material in the pulp and paper mills, while the steam from the pulp and paper mills is used as heat source for the sawmills. It can be concluded that a sawmill and an adjacent pulp and/or paper mill is a favourable starting-point for developing industrial symbiosis and that they together are the central actors in the forest industry, if any can be defined.

Burström and Korhonen (2001) suggest that a municipal authority can act as an initiating, co-ordinating and educating institution and could gather and distribute data and offer decision support. The reason for the unique role of the municipalities is, according to Burström and Korhonen, that they are usually the only type of actor that consider the economic, ecological, and social well-being of the region simultaneously, whereas a single company usually focuses mainly on its own economic well-being.

In the local industrial ecosystem case study (paper II-III), the municipality was involved in LIP (Local Investment Program) subsidy applications concerning the expansion of the district heating networks but apart from that they have not been pro-active in the issues of increased integration and the utilization of local waste heat or material. For example, the municipal authority lacks the resources to attend to the situation at the local waste management site in the local industrial ecosystem case. In that case study, it was also seen that representatives of the municipal authority considered the investments required to be an obstacle to some of the measures proposed, although the investments would be profitable with short pay-off times. The capital must exist and since several of the measures proposed concerned more than one part of the municipality's organization, the problem was "who" was going to pay. Increased integration of energy and material flows concerns areas such as real estate, energy supply, waste management, environmental issues and industrial development. The integration between these divisions in the municipality's organization was weak in the case study and the services offered by regional and local authorities for industrial development mainly focused on a specific company. Some possibilities for development might be to collect and organize information on networks, form work groups across authorities, encourage activities that concern several companies - for example 
$\mathrm{R} \& \mathrm{D}$ and marketing of regional clusters. Moreover, they could provide a forum where the actors can meet and contribute to the enhancement of competences.

In Kalundborg, the waste dealer is not considered to be part of the Industrial Symbiosis since it is their usual business (Christensen, 2007). However, the results from the Kisa study in this work (Papers II-III) indicate that companies with integration as their business concept - ecocycle companies and to some extent energy service companies - can be key actors when developing industrial symbiosis. An energy service company could benefit from waste heat integration; an ecocycle company has incentives to start waste-material co-operations since they are part of their business strategy. They may also have more resources and knowledge about legislation and processes for acquiring development consent etc. Applying for development consent is a demanding task and requires many different resources in the form of internal environmental engineers, external experts and negotiations with various government authorities etc. A small local company or a small municipality often lacks such resources. Barriers relevant for the ecocycle company might be the lack of local focus and that the size of the municipality must be considerable for them to find it attractive to set up business locally. Lack of local focus can also be a barrier to the ESCO having a key position in the development of local industrial ecosystems. 


\section{CONCLUDING DISCUSSION}

In this work, different aspects of industrial symbiosis in the Swedish forest industry were evaluated. In this section, the conclusions are summarized and some areas for future work are presented.

\section{1 Summary of conclusions}

The conclusions and lessons learned from this work can be summarized in the light of the research questions asked at the beginning of this thesis, focused on the research areas occurrence, development and evaluation.

\subsubsection{Can industrial ecosystems or other examples of integration be found in the Swedish forest industry using the industrial symbiosis approach?}

Based on the results of the inventory and on the experience gained from the case studies, the conclusion can be drawn that industrial symbiosis initiatives exist in the Swedish forest industry today. Fifteen BPX networks were found in the inventory and it was concluded that more may possibly be found if the definitions of IS were to be widened, and also by closer examination of the industries in the study. None of these networks were deliberately planned or labelled as IS, however, but they may still lead to increased eco-efficiency and might be further developed.

Comparing the different studies gives rise to some interesting thoughts. The inventory made in paper IV did not include the local industrial ecosystem 
studied and developed in papers II and III. Using the definition of "industrial symbiosis" as presented in paper IV does not find areas and communities with potential and/or planned exchanges, not yet realized. Also, using the "32 heuristic" (at least three different entities exchanging at least two different resources) suggested in literature (Chertow, 2007) and used for analysis in paper IV means excluding integrated biofuel upgrading within an industry, for example the cases studied in paper I, under the banner of industrial symbiosis (at least not unless connected to a minimum of two other entities). Including only "over the fence" co-operations, as is done for example in Kalundborg, would not include biofuel combines either. However, from an environmental perspective it does not matter who is the owner of processes closing the loop. What matters are the benefits of waste- and by-product utilization.

\subsubsection{How have the systems evolved, how can the existing systems be further developed and how can the knowledge be implemented in new systems?}

The human dimensions of increased integration have been evaluated, and the conclusion is that the conditions for implementation differ depending on the type of system considered. The most important conditions common to all systems are a positive attitude from the companies involved, willingness to act and power relations. Lack of resources, imperfect environmental regulations, time frames and the risks involved when adopting new technologies are among the barriers identified. Subsidies such as LIP might be a driving force.

Many authors agree that one way to develop IS is to focus on existing potential (Sterr and Ott, 2004; Chertow, 2007). The co-operations that do not qualify as IS might thus also be interesting from the perspective of development and implementation since some degree of trust and willingness to co-operate probably already exists, which could lead the way for development of further exchanges. In this work, the results from a study attempting a "side-in" approach to development of IS have been presented. By taking a starting point in an area where some kind of co-operation exists it was demonstrated that it is possible to initiate new exchanges involving the actors as much as possible in the process of developing suggestions for improvement. It was seen that one of the most important steps was the 
forming of a forum where the actors could meet. It was also concluded that a good knowledge of the system was important and it was suggested that a company with recycling as a business concept, or an energy service company, could serve as an anchor tenant.

One aspect of the Swedish forest industry which could facilitate industrial symbiosis initiatives is that it works as a cluster, where co-operation, both internal and with outside partners, generates employment, know-how and competence throughout the entire cluster (Swedish Forest Industries Federation, 2004). It has been recognized by several authors that cluster theory and the development of industrial ecology are closely coupled, since networks and co-operation are cornerstones of industrial ecology (Ehrenfeldt, 2000; Cohen-Rosenthal, 2000; Esty and Porter, 1998). The tradition of district heating and use of waste heat from industry in Sweden could also facilitate the introduction of the IS concept since it might make the actors more open to other types of co-operations as well.

\subsubsection{How can the success of industrial ecosystems or other examples of integration be evaluated from an economic and environmental point of view?}

It is possible, but difficult, to evaluate industrial symbiosis initiatives, both qualitatively and quantitatively. In the cases studied here the integration is considered fruitful from the companies' point of view. This could be used for a qualitative discussion about the benefits. In fact, the mere existence of exchanges, which are not supported directly through subsidies, taxes or regulations, imply that they may have benefits. From the environmental perspective, the more efficient use of energy and material achieved through integration, as well as the reduced transportation, can be argued to have benefits although these have not been quantified.

The results from papers V-VI support the assumption of economic and environmental (at least with $\mathrm{CO}_{2}$ as an indicator) benefits of industrial symbiosis. The distribution of costs and benefits among different entities has not been considered. This was due to the attempt to evaluate the benefits from a systems perspective. Even if the integrated system has an overall lower 
system cost in the model; in real life, sharing of these winnings is what really matters for implementation of industrial symbiosis. The MIND method could also be used to evaluate effects on the separate industries generating results that can be used as decision support at a company level when planning industrial symbiosis initiatives in the forest industry.

One important conclusion from the environmental evaluation was that the assumptions made have a significant impact on the results, especially the assumption whether or not biofuel is a limited resource, and the origin of the electricity used. This implies that evaluation of industrial symbiosis, as all environmental assessment, has to be done with great care, adjusting the methods to the specific case and critically examining the results in relation to the assumptions.

\subsubsection{Research contribution in the light of the objective}

The objective of this work was to apply the framework of IS to the Swedish forest industry, both to gain empirical evidence, which can be used for critical analysis and further conceptual development, and to evaluate how the industrial symbiosis approach can contribute to the resource efficiency in the forest industry.

There are several reasons why the IS framework could be useful as an analytical framework for efficient use of material and energy in the forest industry. Firstly, the forest industry is energy intensive, and the pulp and paper mills produce large amounts of waste heat which could be used in other processes and/or DHNs. Although the raw materials are renewable, and often assigned net zero emissions of $\mathrm{CO}_{2}$, it is important to use the harvested wood as efficiently as possible. Since biofuel is not an unlimited resource, saved biofuel can be used to replace other energy carriers elsewhere in the system. Traditionally, by-products such as bark and sawdust have had little value, and therefore the industries have had access to "free" fuel. Although this situation has changed today, there might be inefficiencies remaining in the systems, which may be found using the framework of industrial symbiosis and solved through increased integration. 
The IS framework could also be useful to strengthen the forest industry sector where the industries all rely on the same source for raw material - the forest. The pulp and paper industry, sawmills, particle board industry and upgraded biofuel producers are dependent on each others' by-products, both as raw material and as fuel. Pulp mills partly use wood chips from the sawmill industry as raw material and bark as fuel. The particle board industry uses woodchips and sawdust from sawmills. The sawmills need electricity and steam, which can be delivered from pulp mills for example. Theoretically, there is a balance between heat supply and demand in the forest industry (Svebio, 1998). However, since the industries are not co-located or do not always co-operate, the sawmills also deliver biofuel to district heat boilers. The industry sometimes also has to buy fuel from other suppliers due to technical limitations in the processes. Here, successful IS could contribute to securing deliveries of raw materials as well as saving transportation.

The empirical experience gained through the case studies can be used to critically analyse and develop the framework of IS. One such example is the issue of the system boundaries. In IS a local focus is often taken as the definition includes the reference to 'adjacent' industries, and because this is assumed to reduce transportation. In paper IV it was concluded that by including the requirement that the entities should be 'adjacent' in the IS definition, the number of examples found in the inventory was probably reduced. However, co-location does not necessarily lead to eco-efficiency, as was illustrated and discussed in paper II. With a larger systems view, drawing upon the concept of sustainability, which is a global challenge, it would be necessary to be more flexible in the system boundaries and decide from case to case whether the gain from possible reduced transportation is more important than a potential increase in efficiency that might be gained by advantages of scale or by using the resources elsewhere in the system. Some previous authors have also acknowledged this question, such as Baas and Boons (2004) who argue that the regional system may be forced to grow and increase the number of activities and actors in it if it is to be sustainable in the long run, and Sterr and Ott (2004) who concluded that a larger region is more suitable for industrial ecosystem development. This might lead to a conflict of interests since a local focus might be important to building trust and bonds 
which can lead to increased integration between the companies. However, there is also a risk for misuse of the IS concept as a cover up for other interests, such as a strengthening of the local economy, without considering environmental aspects (cf. Deutz and Gibbs 2004). For utility sharing, such as transportation, buildings, energy system and water exchanges, the local context is of course important.

An additional contribution that the studies of the Swedish forest industry can make to the IS field of research is the fact that it is based mainly on renewable resources. Although much of the theory behind industrial ecology has been developed drawing on the concept of sustainability, many of the leading industrial symbiosis initiatives are based on, or include, oil refineries and/or fossil fuel based power production, including Kalundborg, Alberta, INES Mainport, Brownsville Texas etc. Although Lowe (2001) states that an EIP should be more than a collection of companies making green products, it can hardly be seen as a disadvantage, from a sustainability point of view, if they do. The possibility of an efficient system of energy and material exchanges based mainly on renewable resources could help take IS further along the road towards sustainability.

Other contributions to the IS concept and theories made in the line of this work are for example the suggestion that companies with integration as their business concept be anchor tenants for industrial ecosystems (Paper III), the introduction of the MIND method for evaluation (Paper V-VI), the side-in approach for development of IS (Paper II) and the connection to energy systems studies (e.g. Paper I).

\subsection{Future work}

It is hard to conclude from the historical overview given in section 5.1 whether the degree of integration in the forest industry has decreased or increased since the beginning of the last century. From the work presented in this thesis, it can be assumed that it varies depending upon the values and political decisions of the day, and on other factors than technical aspects such as trends in management style, outsourcing, and company structures. An 
interesting area for future research would be to study how such factors influence possibilities for IS.

Also, the issue of evaluation of IS needs to be further developed. The importance and urgency of this matter has been stressed in recent literature, and both possibilities and difficulties have been illustrated in this thesis. Here, I have only had the time and possibility to scratch the surface of this complex problem however, and I consider it one of the most important issues for further research. 


\section{NOTES}

1. I should perhaps point out that this is my opinion, not necessarily shared by the rest of the IS community, based on extensive reading about and also a visit to Kalundborg.

2. The original case study in Kisa, as presented in section 5.4, was conducted in 2004. However, it is of interest to point out some recent developments in the industrial ecosystem. Firstly, the heat delivery from the sawmill to the DHN suggested by the authors is now in operation. There is a new Energy Service Company which has taken over operation of the DHN; they have negotiated on a new 10-year deal for delivery of heat from the boiler at the paper mill, and they have also managed to close a deal with the sawmill, who have invested in a district heating economizer, a new system for handling of bio-fuel and some other modernizations which opens up the possibility for heat delivery to the DHN. In a first step, a limited capacity of 3-5 MW from the boiler is being delivered to the DHN, but the sawmill are investigating the possibilities for flue gas condensation and delivery of waste-heat as suggested in the case study.

Also, the localization of a pellet production plant in Kisa is presently under investigation.

These recent developments are of interest to the discussion of human dimensions since they support some of the conclusions drawn in paper III and bring some additional light to the discussion about local roots and power relations in the companies. The most interesting development is the delivery of heat from the sawmill to the DHN which has now been realized. At the time of the case study, neither the sawmill nor the ESCO showed great interest in this arrangement, for the reasons stated above. So the question arises - why did they change their minds? By investigating the development and changes made in the companies during the time that has passed since the case study, the general picture becomes clear. 
First, there is a new ESCO in Kisa, which has bought the DHN and the boiler from the old ESCO. The new company is smaller and has more local roots. The representative from the new ESCO states that they see large potential in the overall development of the Kisa area. Also, it is possible that the sale of the Kisa system was under consideration already at the time of our case study, which would have prevented the ESCO to be pro-active in the development of the system.

A second, important, parameter in the realization of the heat delivery is the developments at the sawmill. One important factor is probably the fact that the sawmill has new management, and the person presently in charge there has taken an interest in developing the energy system and making it more efficient. This could support the theories on the importance of an enthusiast to realize co-operation. However, there is an additional factor behind this sudden change of attitude at the sawmill. The group of companies that the sawmill belongs to has hired a consultant to investigate the possibilities to make the energy systems more efficient, and this consultant has also made an analysis of the Kisa sawmill. This support from the central organization on the questions of energy efficiency has probably had a great impact on the decision to realize the district heating delivery and the modernizations of the boiler. This supports the theory as to the importance of the power relations in the companies - if the central organization takes an active part in supporting a project it is more easily realized than if the suggestion comes from the local company themselves.

3. One of the business strategies of the ecocycle company is to sun and wind dry sludge and fibre residues since this facilitates both their transportation and their use as an energy source etc.

4 This can also be discussed, however. See Grönkvist (2005, p.16-17) for a discussion of market mechanisms and other issues that could lead to questions about the switch from an oil-fired boiler to waste-heat utilization which might seem obviously efficient at a cursory glance. 
5. For example, the Swedish Forest Industry Federation state in their code of conduct for LCA that "When evaluating electrical energy consumption the national grid production mix shall be used." without references to the nature of the study (descriptive/attributional etc). (Swedish Forest Industry Federation, 2007b). 


\section{REFERENCES}

Ahnland, R (1997) 'Sågverk som energiproducent. Effektiv torkning ger mer biobränsle' (Sawmill as energy producer. Efficient drying gives more biofuel, in Swedish), Energimagasinet, no. 7:97, pp. 20-22.

Alter, C. and Hage, J. (1993) Organizations Working Together, Sage Library of Social Research 191, Sage Publications, California.

Ammenberg, J. (2003) Do Standardised Environmental Management Systems Lead to Reduced Environmental Impacts? Doctoral Dissertation. Environmental Technology and Management, Department of Mechanical Engineering, Linköping University, Sweden.

Andersson, E., Frimanzon, A., Vidlund, A. (2003) Energieffektiv biobränsleforrälling $i$ skogsindustrin, ('Energy-efficient biofuel upgrading in the forest industry', in Swedish), Energy Systems Programme Report No. 24, Linköping Institute of Technology, Linköping, 2003.

Andersson, E. (2007) Benefits of Integrated Upgrading of Biofuels in Biorefineries Systems Analysis. Dissertation, Chalmers University of Technology, Göteborg, Sweden.

Atterhem, L. (2001) Integrerad bränslefabrik med kraftvärmeanläggning - en utvärdering, (Integrated fuel factory and COP-plant - an evaluation, In Swedish). Värmeforsk Service AB, Skellefteå, Sweden.

Ayres, R.U. and Ayres, L.W. (2002) eds. A bandbook of industrial ecology. Edward Elgar, Cheltenham, UK.

Baas, L. (1998) 'Cleaner production and industrial ecosystems, a Dutch experience'. Journal of Cleaner Production, Vol. 6, pp. 189-197.

Baas, L.W., Boons, F.A. (2004) 'An industrial ecology project in practice: exploring the boundaries of decision-making levels in regional industrial systems'. Journal of Cleaner Production, Vol. 12, pp. 1073-1085. 
Barringer, B.R. and Harrison, J.S. (2000) 'Walking a Tightrope: Creating Value Through Inter-organisational Relationships'. Journal of Management, Vol. 26, No. 3, pp. 367-403.

van Beers, D., Corder, G., Bossilkov, A., van Berkel, R. (2007) 'Industrial symbiosis in the Australian minerals industry - The cases of Kwinana and Gladstone'. Journal of Industrial Ecology, Vol. 11, No. 1, pp. 55-72.

Bengtsson C., Karlsson M., Berntsson T. and Söderström M. (2002) 'Costefficient CO2-reduction in the pulp and paper industry - a case study'. In proceedings: 1st International Conference on Sustainable Energy Technologies, Porto, Portugal, 12-14 June 2002.

van Berkel, R. (2006) Regional Resource Synergies for Sustainable Development in Heavy Industrial Areas: an overview of opportunities and experiences. Curtin University of Technology: Perth (WA), Australia.

van Berkel, R. and Bossilkov, A. (2004) Sustainable Development in the Australian Minerals processing Industry. Green processing 2004. $2^{\text {nd }}$ International Conference on Sustainable Processing of Minerals and Metals, Fremantle (WA), Australia.

van Berkel, R., Willems, E., Lafleur, M. (1997) 'Development of an industrial ecology toolbox for the introduction of industrial ecology in enterprises - I'. Journal of Cleaner Production, Vol. 5, Nos. 1-2, pp. 11-26.

Billow, A. (1928) Bilder från Sverige : fembundratjugutre originalfotografier, belysande natur och kultur $i$ gangen tid och nutid. (Pictures from Sweden, in Swedish). Sv. journalen, Stockholm.

Bioenergi no.1 2002, p. 11, www.novator.se/bioenergy, 2002-11-10

Bionorr (2002) Company information, www.bionorr.com, 2003-01-15 
Boons, F.A., Baas, L.J. (1997) 'Types of industrial ecology: the problem of coordination'. Journal of Cleaner Production, Vol. 5, Nos.1-2, pp.79-80.

Brings Jacobsen, N. (2006) 'Industrial symbiosis in Kalundborg, Denmark. A quantitative assessment of economic and environmental aspects'. Journal of Industrial Ecology, Vol. 10, Nos. 1-2, pp. 239-255.

Bruhn-Tysk, S. and Eklund, M. (2000) 'System boundaries in environmental impact statements for biofuelled energy plants in Sweden'. In: Proceedings from the $3^{\text {rd }}$ Nordic EIA conference Environmental impact assessment and strategic environmental assessment, 22-23 November 1999, Karlskrona, Sweden.

Bruhn-Tysk, S. and Eklund, M. (2002) 'What about natural resources in environmental impact statements for Swedish bioenergy plants?'. Journal of Environmental Assessment Policy and Management, Vol. 4, pp. 67-82.

Burström, F. and Korhonen, J. (2001) 'Municipalities and industrial ecology: Reconsidering municipal environmental management'. Sustainable Development, Vol. 9, pp. 36-46.

Casavant, T.E. and Côté, R.P. (2004) 'Using chemical process simulation to design industrial ecosystems’. Journal of Cleaner Production, Vol. 12, pp. 901-908.

Chertow, M. R. (1999a) 'The Eco-industrial Park Model Reconsidered'. Journal of Industrial Ecology, Vol. 2, No. 3, pp. 8-10.

Chertow, M. R. (1999b) 'Industrial Symbiosis: a multi-firm approach to sustainability'. Proceedings of the 1999 Greening of Industry Network Conference, 8 ${ }^{\text {th }}$, Chapel Hill, N. Carolina.

Chertow, M. R. (2000) 'Industrial Symbiosis: Literature and Taxonomy'. Annual Review of Energy and the Environment, Vol. 25, pp. 313-337.

Chertow, M. R. (2007) '"Uncovering" Industrial Symbiosis'. Journal of Industrial Ecology, Vol. 11, No. 1, pp. 11-30. 
Chertow, M. R., Lombardi, D. R. (2005) 'Quantifying Economic and Environmental Benefits of Co-Located Firms'. Environmental Science \& Technology. Vol. 39, No. 17, pp. 6535-6541.

Christensen, J. 2007. Presentation in Kalundborg, Denmark. 12 April 2007.

Clift, R. and Wright, L. (2000) 'Relationships between environmental impacts and added value along the supply chain'. Technological forecasting and social change, Vol. 65, pp. 281-295.

Cohen-Rosenthal, E. (2000) 'A Walk on the Human Side of Industrial Ecology'. American Behavioral Scientist, Vol. 44, No. 2, pp. 245-264.

Côté R.P. and Cohen-Rosenthal E. (1998) 'Designing eco-industrial parks: a synthesis of some experience'. Journal of Cleaner Production, Vol. 6, pp. 181-188.

Desrochers P. (2002a). 'Regional development and inter-industry recycling linkages: some historical perspectives'. Entrepreneurship \& Regional Development, Vol. 14, pp. 49-65.

Desrochers P. (2002b). 'Industrial ecology and the rediscovery of inter-firm recycling linkages: historical evidence and policy implications'. Industrial and Corporate Change, Vol. 11, No. 5, pp. 1031-1057.

Desrochers, P. (2004) 'Industrial symbiosis: the case for market coordination'. Journal of Cleaner Production, Vol. 12, pp. 1099-1110.

Deutz, P. and Gibbs, D. (2004) 'Eco-industrial development and economic development: industrial ecology or place promotion?'. Business Strategy and the Environment, Vol. 13, pp. 347-362.

Deutz, P. and Gibbs, D. (2007) 'Industrial Ecology and Regional Development: Eco-Industrial Development as Cluster Policy'. Regional Studies (forthcoming). 
Diwekar, U. (2005) 'Green process design, industrial ecology, and sustainability: A systems analysis perspective'. Resources, Conservation and Recycling, Vol. 44, pp. 215-235.

Diwekar, U. and Small, M.J. (2002) 'Process analysis approach to industrial ecology'. In: Ayres R.U. and Ayres L.W eds. A bandbook of industrial ecology, Edward Elgar, Cheltenham, UK.

Ehrenfeld, J. (1997) 'Industrial ecology: A framework for product and process design'. Journal of Cleaner Production, Vol. 5, Nos. 1-2, pp. 87-95.

Ehrenfeld, J and Gertler, N. (1997) 'Industrial ecology in practice: The evolution of interdependence at Kalundborg'. Journal of Industrial Ecology, Vol. 1, No. 1, pp. 67-79.

Ehrenfeld, J. (2000) 'Industrial ecology: paradigm shift or normal science?'. American Behavioral Scientist, Vol. 44, No. 2, pp. 229-244.

Ehrenfeld, J. and Chertow, M. (2002) 'Industrial symbiosis: the legacy of Kalundborg'. In R.U. Ayres and L.W. Ayres (eds.), A bandbook of industrial ecology. Edward Elgar, Cheltenham, UK.

Ekvall, T., Tillman, A-M., Molander, S. (2005) 'Normative ethics and methodology for life cycle assessment'. Journal of Cleaner Production, Vol. 13, pp. 1225-1234.

Ekvall, T. Weidema, B.P. (2004) 'System Boundaries and Input Data in Consequential Life Cycle Inventory Analysis'. International Journal of Life Cycle Analysis. DOI: http://dx.doi.org/10.1065/lca2004.03.148.

Erkman, S. (1997) 'Industrial ecology: an historical view'. Journal of Cleaner Production, Vol. 5, Nos.1-2, pp. 1-10. 
Esty, D.C. and Porter, M.E. (1998) 'Industrial Ecology and Competitiveness: Strategic implications for the firm', Journal of Industrial Ecology, Vol 2, No. 1, pp. $35-43$.

Finnveden, G. (2000). 'On the Limitations of Life Cycle Assessment and Environmental Systems Analysis Tools in General'. International Journal of Life Cycle Assessment, Vol. 5, No. 4, pp. 229-238.

Finnveden, G., Moberg, A. (2005) 'Environmental systems analysis tools - an overview'. Journal of Cleaner Production, Vol. 13, pp. 1165-1173.

Frosch, R., Gallopoulos, N. (1989) 'Strategies for Manufacturing'. Scientific American, Vol. 261, No.3, pp. 144-152.

Gibbs, D., Deutz, P., Proctor, A. (2005) 'Industrial Ecology and Ecoindustrial Development: A Potential Paradigm for Local and Regional Development?' Regional Studies, Vol. 39, No. 2, pp. 171-183.

Graedel, T.E and Allenby, B.R. (2003) Industrial Ecology, Second Edition. Pearson Education Inc. Upper Saddle River, New Jersey.

Grönkvist, S. 2005. All $\mathrm{CO}_{2}$ molecules are equal, but some $\mathrm{CO}_{2}$ molecules are more equal than others. Doctoral Thesis. Division of Energy Processes, Department of Chemical Engineering and Technology, Royal Institute of Technology, Stockholm, Sweden.

Grönkvist, S., Marbe, Å., Möllersten, K., Sundgren, D. (2001) Fyra Studier av energisamarbeten $i$ Sverige (Four studies of energy cooperations in Sweden. In Swedish), Energy Systems Program Report No. 18, ISSN 1403-830, Linköping Institute of Technology, Linköping, Sweden.

Grönkvist, S., Sjödin, J., Westermark, M. (2003) 'Models for assessing net $\mathrm{CO} 2$ emissions applied on district heating technologies'. International Journal of Energy Research, Vol. 27, pp. 601-613. 
Hardy, C. and Graedel, T. (2002) 'Industrial ecosystems as food webs' Journal of Industrial Ecology, Vol. 6, No. 1, pp. 29-38.

Harper, E.M., Graedel, T.E. (2004) Industrial ecology: a teenager's progress', Technology in Society, Vol. 26, pp.433-445.

Heeres, R. R., Vermeulen, W. J. V. and de Walle, F. B. (2004), 'Eco-industrial park initiatives in the USA and the Netherlands: first lessons', Journal of Cleaner Production, Vol. 12, pp. 985-995.

IPCC (1997) Revised 1996 Guidelines for National Greenhouse Gas Inventories, Workbook (Volume 2) Energy, UK Meteorological Office, Bracknell.

Johansson, L. and Westerlund, L. (2000) 'An open absorption system installed at a sawmill. Description of a pilot plant used for timber and bio-fuel drying', Energy, Vol. 25, pp. 1067-1079.

Karlsson, M. and Sandberg, P. (2007). The MIND method: a flexible decision support for optimization of industrial energy systems - principles and case study, Submitted to European Journal of Operational Research.

Korhonen, J. (2001a), 'Regional industrial ecology: examples from regional economic systems of forest industry and energy supply in Finland', Journal of Environmental Management, Vol. 63, pp. 367-375.

Korhonen, J. (2001b) 'Co-production of heat and power: an anchor tenant of a regional industrial ecosystem', Journal of Cleaner Production, Vol. 9, pp. 509517.

Korhonen, J., von Malmborg, F., Strachan, P., Ehrenfeld, J. (2004) 'Management and policy aspects of industrial ecology: an emerging research agenda', Business Strategy and the Environment, Vol. 13, pp. 289-305. 
Korhonen, J., Niemeläinen, H. and Pulliainen, K. (2002), 'Regional industrial recycling network in energy supply - the case of Joensuu City, Finland', Corporate Social Responsibility and Environmental Management, Vol. 9, pp. 170-185.

Korhonen, J., Wihersaari, M., Savolainen, I. (2001) 'Industrial ecosystem in the Finnish forest industry: using the material and energy flow model of a forest ecosystem in a forest industry system', Ecological Economics, Vol. 39, pp. 145-161.

Korhonen, J., Wihersaari, M., Savolainen, I. (1999) 'Industrial Ecology of a Regional Energy Supply System: the case of Jyväskylä region, Finland', Greener Management International, No. 26, pp. 57-59.

Laestadius, S. (1996) Vid "lagteknologins" frontlinjer - konsten att tillverka $14000 \mathrm{~m} 2$ papper per minut och tekniken och industrin bakom den' (The art of manufacturing $14,000 \mathrm{~m} 2 \mathrm{paper} / \mathrm{min}$ and the technology and industry behind it. In Swedish). Department of Industrial Economy and Organisation, Royal Institute of Technology, Stockholm.

Laestadius, S. (1998) 'Technology level, knowledge formation, and industrial competence in paper manufacturing', In: Eliasson G, Green C, McCann CR, (Eds). Microfoundations of Economic Growth: A Schumpeterian Perspective. Ann Arbor, MI: The University of Michigan Press.

Laestadius, S. (2000) 'Biotechnology and the potential for a radical shift of technology in forest industry', Technology Analyses \& Strategic Management, Vol. 12, No. 2, pp. 193-212.

Lambert, A.J.D. and Boons, F.A. (2002) 'Eco-industrial parks: stimulating sustainable development in mixed industrial parks', Technovation, Vol. 22 pp. 471-484.

van Leeuwen, M.G., Vermeulen, J.W., and Glasbergen, P. (2003) 'Planning eco-industrial parks: an analysis of Dutch planning methods', Business Strategy and the Environment, Vol. 12, pp. 147-162. 
Lifset, R. and Graedel, T.E. (2002) 'Industrial Ecology: goals and definitions'. In: Ayres, R.U. and Ayres, L.W. (eds.). A handbook of industrial ecology, Edward Elgar, Cheltenham, UK.

Lowe, E.A. (1997) 'Creating by-product resource exchanges: strategies for eco-industrial parks', Journal of Cleaner Production, Vol. 5 Nos. 1-2, pp. 57-65.

Lowe, E.A. (2001) Eco-industrial Park Handbook for Asian Developing Countries. A Report to Asian Development Bank, Environment Department, Indigo Development, Oakland, CA.

Magnusson, L. (1991) Produktion och förädling av bränslen vid skogsindustrin möjligheter och forrutsättningar (Production and upgrading of fuel in the forest industry - possibilities and conditions, in Swedish), Vattenfall Utveckling och miljö.

von Malmborg, F. (2004) Networking for knowledge transfer: towards an understanding of local authority roles in regional industrial ecosystem management', Business Strategy and the Environment, Vol. 13, pp. 334-346.

Mared, J. (2002), "Pellets Production Connected to District Heating" Pellets 2002 First World Conference on Pellets, 2002-09-04.

Mirata, M. (2005) Industrial Symbiosis: A tool for more sustainable regions? Doctoral Dissertation, IIIEE, University of Lund, Sweden.

Mirata, M. and Emtairah, T. (2005) 'Industrial Symbiosis Networks and the Contribution to Environmental Innovation: The case of the Landskrona industrial symbiosis programme' Journal of Cleaner Production Vol. 13, Nos. 1011, pp. 993-1002.

Möllersten, K. and Sandberg, P. (2004) 'Collaborative energy partnerships in relation to development of core business focus and competence - a study of Swedish pulp and paper companies', Business Strategy and the Environment, Vol. 13, pp. $78-95$. 
Möllersten, K. and Westermark, M. (2001) 'Outsourcing of energy facilities in the pulp and paper industry - motives for outsourcing partnerships between energy companies and pulp and paper manufacturers', Proceedings of the World Energy Council, $18^{\text {th }}$ Congress, Buenos Aires.

National Governors Association (2002) A governor's guide to cluster-based economic development, http: \\www.nga.org

Nilsson, K. (1993) Cost-Effective Industrial Energy Systems - Multiperiod Optimization of Operating Strategies and Structural Choices, Linköping Studies in Science and Technology. Dissertation No. 315, Linköping University, Linköping, Sweden.

NUTEK, (2001) Regionala vinnarkluster - en fråga om kompetensförsöryining, värdeskapande relationer och barriärbrytande visioner. Strategidokument fran Klustergruppen (Regional winning clusters, in Swedish) NUTEK.

Nyström, I. and Cornland, D.W. (2003) 'Strategic choices: Swedish climate intervention policies and the forest industry's role in reducing $\mathrm{CO}_{2}$ emissions', Energy Policy Vol. 31, pp. 937-950.

Onita, J.A. (2006) 'How does industrial symbiosis influence environmental performance' M.Sc. 'Thesis in Environmental Science, Department of Environmental Technology and Management, Institute of Technology, Linköping University, Linköping, Sweden.

O'Rourke, D., Connelly, L., Koshland, C.P. (1996) 'Industrial Ecology - a critical review', International. Journal of Environment and Pollution, Vol. 6, Nos. 2-3, pp. 89-112.

Petersson, K. (2006) Industriell Ekologi i Sverige? Förekomst av integration av material- och energiflöden i skogsindustrin (Industrial Ecology in Sweden? Occurrence of integration of material and energy flows in the forest industry, In Swedish) M.Sc. Thesis 
in Energy Systems, Department of Environmental Technology and Management, Institute of Technology, Linköping University, Linköping, Sweden.

Pettersson, A. (2002) 'Pellets production in an energy combine', Presented at Pellets 2002, First World Conference on Pellets, Stockholm.

Russel, A., Ekvall, T., Baumann, H. (2005) Editorial, 'Life cycle assessment introduction and overview'. Journal of Cleaner Production, Vol. 13, pp. 12071210.

Sandberg, P. and Söderström, M. (2003) 'Industrial energy efficiency: the need for investment decision support from a manager perspective', Energy Policy, Vol 31, No. 15, pp. 1623-34.

Sandberg, P., Larsson, M., Dahl, J., Söderström, M., Vourinen, H. (2004) 'In search of Stability - investigating flexible and stable production strategies for an optimised steel plant.' Scanmet II. Proceedings of the $2^{\text {nd }}$ international Conference on Process Development in Iron and Steelmaking: Sweden; 2004.

Sandberg, P. and Larsson, M. (2004) Analysing the cost, energy use and environmental performance of an integrated steel plant by applying a multiobjective approach. Submitted to Energy - the international journal.

Schwarz, E. J. and Steininger, K.W. (1997). Implementing Nature's Lession: The industrial recycling network enhancing regional development. Journal of Cleaner Production, Vol. 5, Nos. 1-2, pp. 47-56.

SEA (2002) Marginal elproduktion och $\mathrm{CO}_{2}$ utsläpp $i$ Sverige (Marginal Electricity Production and $\mathrm{CO}_{2}$ Emissions in Sweden, in Swedish). Report ER14:2002, Swedish Energy Agency, Eskilstuna, Sweden.

SEA (2006) Energiläget 2006 (Energy in Sweden 2006', in Swedish), ET 2006:43. Swedish Energy Agency, Eskilstuna. 
Singh, A., Lou, H.H., Yaws, C.L., Hopper, J.R., Pike, R.W. (2006) Environmental impact assessment of different design schemes of an industrial ecosystem, Resources Conservation \& Recycling. Doi: 10.1016/j.resconrec.2006. 10.002 .

Sjödin, J., Grönkvist, S. (2004) Emissions accounting for use and supply of electricity in the Nordic market. Energy Policy, Vol. 32, pp. 1555-1564.

Snäkin, J-P. (2003) Wood energy and greenhouse gas emissions in the heating energy system of North Karelia, Finland: and Industrial Ecology approach. Academic Dissertation, Faculty of Forestry, University of Johensuu, Finland.

Sterr, T., Ott, T. (2004) 'The industrial region as a promising unit for ecoindustrial development - reflections, practical experience and establishment of innovative instruments to support industrial ecology', Journal of Cleaner Production, Vol. 12, pp. 947-965.

Strukturutredningen (1971) Svensk skogsindustri i omvandling - utvecklingen sedan 1950 (Developments in Swedish forest industry since 1950, in Swedish). Skogsindustriernas Samarbetsutskott - Strukturutredningen Band 1, Grafikon AB, Stockholm.

Svebio (1998) Möt bioenergin 8 (Information about biofuels, in Swedish), www.svebio.se

Svensson, N., Roth, L., Eklund, M., Mårtensson, A. (2006) Environmental relevance and use of energy indicators in environmental management and research. Journal of Cleaner Production, Vol. 14, pp. 134-145.

Swedish Forest Industries Federation (2001) Energiförbrukning $i$ massa- och pappersindustrin 2000, (Energy demand in the pulp and paper industry 2000, in Swedish). Brommatryck \& Brolins, Sweden. 
Swedish Forest Industries Federation (2007a) Skogsindustrin - En faktasamling 2006. (The Swedish Forest Industries 2006, facts and figures. In Swedish) Stockholm.

Swedish Forest Industry Federation (2007b) < http://www.skogsindustrierna. org/>Accessed 11 May 2007.

Swedish Government Energy Bill (2003) Electricity Certificates to Promote Renewable Energy Sources. 2002/03:40, Sweden (in Swedish).

Symbiosis Institute (2007) www.symbiosis.dk, accessed April 10, 2007

Tyteca, D., Carlens, J., Berkhout, F., Hertin, J., Wehrmeyer, W., Wagner, M. (2002) 'Corporate environmental performance evaluation: Evidence from the MEPI project'. Business Strategy and the Environment, Vol. 11, pp.1-13.

Vidlund, A. (2004) Sustainable production of bio-energy products in the sawmill industry. Licentiate Thesis, Energy Processes, KTH, Stockholm.

Wahlund, B. (2003) Rational bioenergy utilisation in energy systems and impacts on $\mathrm{CO}_{2}$ emissions. Doctoral thesis, Department of Chemical Engineering and Technology, Royal Institute of Technology: Stockholm.

Wahlund, B., Yan, J. and Westermark, M. (2002) 'A total system of fuel upgrading by drying biomass feedstock for cogeneration: a case study of Skellefteå bioenergy combine’, Biomass Bioenergy, Vol. 23, pp. 271-81.

WBCSD (2000) Eco-efficiency: creating more value with less impact. World Business Council for Sustainable Development, Geneva.

Wibeck, V. (2000) Fokusgrupper: om fokuserade gruppintervjuer som undersökningsmetod, (Focus groups: focused group interviews as a research method, in Swedish). Studentlitteratur, Lund. 
Yin, R. K. (1994) Case study Research, Design and methods. Sage Publications INC, Thousand Oaks, California. 